\title{
Optimization and comparison of heat and ultrasound assisted extraction techniques to obtain anthocyanin compounds from Arbutus unedo L. Fruits
}

\author{
Cecilia Jiménez López ${ }^{\mathrm{a}}$, Cristina Caleja ${ }^{\mathrm{a}, \mathrm{b}}$, M.A. Prieto ${ }^{\mathrm{a}, \mathrm{c}}$, Maria Filomena Barreiro ${ }^{\mathrm{b}}$, \\ Lillian Barros ${ }^{\mathrm{a}, *}$, Isabel C.F.R. Ferreira ${ }^{\mathrm{a}, *}$ \\ a Centro de Investigação de Montanha (CIMO), Instituto Politécnico de Bragança, Campus de Santa Apolónia, 5300-253 Bragança, Portugal \\ ${ }^{\mathrm{b}}$ Laboratory of Separation and Reaction Engineering - Laboratory of Catalysis and Materials (LSRE-LCM), Polytechnic Institute of Bragança, Campus Santa Apolónia, \\ 1134, 5301-857 Bragança, Portugal \\ ${ }^{c}$ Group, Faculty of Food Science and Technology, University of Vigo, Ourense Campus, E32004 Ourense, Spain
}

\section{A R T I C L E I N F O}

\section{Keywords:}

Arbutus unedo L. fruits

Anthocyanins

Heat and ultrasound assisted extractions

Response surface methodology

\begin{abstract}
A B S T R A C T
The goal of this study was to compare anthocyanin extraction from Arbutus unedo L. fruits, by using two techniques assisted by different energy sources, heat and ultrasound. In order to obtain the conditions that maximize anthocyanin extraction, a response surface methodology was applied using the circumscribed central composite design of three variables with five levels. Three anthocyanin compounds were identified by HPLC-DAD-ESI/MS, being cyanidin-3-glucoside the main molecule. Heat assisted extraction proved to be the most effective method at $5 \mathrm{~min}, 90{ }^{\circ} \mathrm{C}$ and $80 \%$ of ethanol, yielding $51.2 \%$ of extract, with a total anthocyanin content of $382.4 \mu \mathrm{g} / \mathrm{g}$ dried fruit, and $744.6 \mu \mathrm{g} / \mathrm{g}$ extract. These response values were slightly improved by studying the solid/liquid effect at the optimal conditions in dose-response format, showing steady extraction values from 5 to $40 \mathrm{~g} / \mathrm{L}$. Results show the possibility of using A. unedo fruits as a source of anthocyanin compounds for industrial applications.
\end{abstract}

\section{Introduction}

Since ancient times, food industry is committed with the continuous improvement of food safety and quality, while trying to satisfy consumer's requirements (Lambot et al., 2004; Martins, Roriz, Morales, Barros, \& Ferreira, 2016; Wissgott \& Bortlik, 1996). Natural extracts can be sourced in a large number of plant materials and includes primary and secondary metabolites as antioxidants, essential oils, proteins, fats, dietary fibers, pigments, and even polysaccharides (Khadhraoui et al., 2018). The current food processing technological results are a range of miscellaneous properties used for the texturing, preservative or coloring, and as active compounds in cosmetics, food supplements or pharmaceuticals (Carocho, Morales, \& Ferreira, 2015).

Colorants are one of the most important additives in terms of marketing since their presence is considered to influence customer's perceptions, choices and preferences. In fact, color can condition the market success or failure of a food product (Carocho, Barreiro, Morales, \& Ferreira, 2014). Therefore, in order to make food products more attractive, color have been added, either by means of natural or artificial substances (Lee, Lee, \& Choung, 2011; Martins et al., 2016). Nonetheless, artificial additives are being associated with several undesirable effects such as allergic pathologies or mood changes in children, mostly hyperactivity. In opposition, natural colorants, besides being considered generally harmless, they can display a double action, i.e. coloring and bioactive effects (e.g., antioxidant activity) (Albuquerque et al., 2016). Thus, natural colorants, mainly the ones obtained from plants, are gaining industrial importance and consumer's acceptance pushing food industry to search for effective natural solutions to replace artificial ones (Pinela \& Ferreira, 2017).

Anthocyanins, which belong to the parent class of flavonoids, are water-soluble glycosides, secondary metabolites of plants and responsible for a wide range of cyan colors present in nature, ranging from red to blue, including purple, orange and brown (Cavalcanti, Santos, \& Meireles, 2011). Up to 150 different structures are known, being the most important ones pelargonidin, cyanidin, petunidin, malvidin, delphinidin and peonidin derivatives. Cyanidin-3-glucoside is particularly important since it is the most widespread anthocyanin in nature, thus often taken as the standard for the quantification of anthocyanin compounds. Several studies have shown that extracts rich in anthocyanins have beneficial effects in health presenting antioxidant, antibiotic, chemoprotective and antidiabetic activities (Cimino, Ambra, Canali, Saija, \& Virgili, 2006). The main source of anthocyanins is grape

\footnotetext{
* Corresponding authors.

E-mail addresses: iferreira@ipb.pt, lillian@ipb.pt (I.C.F.R. Ferreira).
} 
skin, although red berries such as blackberries, raspberries, cherries and radishes are also used (Chen, Zhao, \& Yu, 2015; Rodrigues, Fernandes, de Brito, Sousa, \& Narain, 2015). However, due to the current demand for these natural colorants, other potential natural sources are under research. This include Arbutus unedo L., commonly known as strawberry-tree, a shrub used as ornamental plant mainly in the gloomy Mediterranean areas (Albuquerque et al., 2016). Their fruits are popularly eaten and used to produce beverages presenting, in addition, several anthocyanins whose content increases with maturity, making them a potential and interesting natural source of this family of compounds.

Rich extracts in anthocyanins are obtained using solid-liquid extraction which is often time and energy consuming, induce the use of huge amount of water or petroleum solvents harmful for environment and users and generate large quantity of waste (Chemat, Rombaut, Meullemiestre, et al., 2017; Chemat, Zill-E-Huma, \& Khan, 2011; Khadhraoui et al., 2018). The combination of these facts with the recent trends in the increasing interest to environmental, economic and safety considerations, extraction techniques have largely focused on finding solutions with sustainable and green values to implement in food processing, cosmetic and pharmaceutical industries (Chemat, Rombaut, Meullemiestre, et al., 2017). Many scientific studies in the last two decades were developed to help industrials to meet this new challenges, substitute their traditional process by a more ecologic and competitive technique of extraction (Khadhraoui et al., 2018). In this regard, the common conventional extraction process to obtain natural colorants from plant based materials is the heat assisted extraction (HAE), because it brings efficient results through a simple process (Chemat, Rombaut, Sicaire, et al., 2017). However, various novel techniques including ultrasound-assisted extraction, microwave-assisted extraction, supercritical fluid extraction, and accelerated solvent extraction have been developed for the extraction of nutraceuticals from plants in order to shorten the extraction time, decrease the solvent consumption, increase the extraction yield, and enhance the quality of extracts. The novel extraction techniques have become relatively mature and some potential applications for the extraction of nutraceuticals from solid plant matrices have been reported (Wang \& Weller, 2006). In this regard, the ultrasound assisted extraction (UAE) technique has demonstrated high recovery rates (Chemat et al., 2011). The choice between these techniques, as well as the conditions in which they are carried out, depend on the chosen natural matrix, used solvent, energy consumption and time, being advantageous to proceed with their optimization (Chemat, Rombaut, Meullemiestre, et al., 2017; Pinela et al., 2016). Such optimization is commonly carried out through the application of mathematical models, such as the response surface methodology (RSM), whose design allows the simultaneous optimization of the variables taking into account complex variable interactions, adding the prediction and maximization of the responses (Bezerra et al., 2008; Ferreira et al., 2007).

In the aforementioned context, the objective of the present study was to optimize the extraction conditions of anthocyanins from fruits of A. unedo. Two of the extraction methodologies largely used HAE and UAE were studied and compared. The joint effect of the relevant variables for each technique, to maximize anthocyanins extraction yield, was described through RSM, contributing to the understanding of the real potential of anthocyanins obtainment from $A$. unedo for industrial applications.

\section{Material and methods}

\subsection{Samples}

Arbutus unedo L. fruit samples were obtained by a local manufacturer of Torre de Moncorvo, Portugal. The fruit samples were immediately submitted to a lyophilization process (FreeZone 4.5 model 7750031, Labconco, Kansas, USA) and reduced to a fine powder
( $\sim 20$ mesh). The obtained powder was carefully mixed to ensure sample equality, protected from light and stored at $-20^{\circ} \mathrm{C}$ (freezer) until analysis.

\subsection{Extraction techniques}

Two extractions techniques (HAE and UAE) were used and compared. In both, the solid/solvent ratio was kept constant at $30 \mathrm{~g} / \mathrm{L}$ ). The extraction processes performed are briefly described:

\subsubsection{Heat assisted extraction (HAE)}

The powder sample material $(600 \mathrm{mg})$ were placed in a reactor with $20 \mathrm{~mL}$ of the selected solvent (different ratios of ethanol:water with $0.05 \%$ of hydrochloric acid, $\mathrm{pH}=4$ ). The temperature was controlled by using a thermostatic water-bath with continuous electro-magnetic stirring (500 rpm) agitation (Albuquerque et al., 2016). The controlled variables and tested ranges were: time ( $t$ or $X_{1}, 30$ to $150 \mathrm{~min}$ ), temperature ( $T$ or $X_{2}, 30$ to $90^{\circ} \mathrm{C}$ ) and ethanol content ( $S$ or $X_{3}, 0$ to $100 \%$ ).

\subsubsection{Ultrasound-assisted extraction (UAE)}

The UAE was carried out in an ultrasonic device (QSonica sonicators, model CL-334, Newtown, CT, USA) inserting $1.5 \mathrm{~g}$ of the powder sample material in the reactor with $50 \mathrm{~mL}$ of solvent (different ratios of ethanol:water with $0.05 \%$ of hydrochloric acid, $\mathrm{pH}=4$ ). The controlled variables and tested ranges were: time ( $t$ or $X_{1}, 3$ to $45 \mathrm{~min}$ ), ultrasound power ( $P$ or $X_{2}, 100$ to $500 \mathrm{~W}$ with a frequency of $20 \mathrm{kHz}$ ) and ethanol content ( $S$ or $X_{3}, 0$ to $100 \%$ ). During the extraction the temperature was monitored to keep it below $30-35^{\circ} \mathrm{C}$ using a waterbath with ice (Albuquerque et al., 2016).

\subsection{Identification and quantification of anthocyanin compounds}

The extracted solutions were centrifuged and filtered through a Whatman paper filter $\mathrm{n}^{\circ} 4$ to remove the suspended solids. The solvent was evaporated at $35^{\circ} \mathrm{C}$ and the extracted residue was quantified. Afterwards, the extracted residues were re-dissolved in acidified water $(0.05 \%$ of hydrochloric acid, $\mathrm{pH}=4)$ and filtered through a LC filter disk (nylon filter $0.2 \mu \mathrm{m}, 25 \mathrm{~mm}$ diameter, Whatman ${ }^{\mathrm{TM}}$, GE Healthcare, Buckinghamshire, UK). HPLC-DAD-ESI/MSn (Dionex Ultimate 3000 UPLC, Thermo Scientific, USA) equipped with a C18 column (Waters Spherisorb S3 ODS-2, $3 \mu \mathrm{m}, 4.6 \times 150 \mathrm{~mm}$ ) was used for the identification and quantification of anthocyanin compounds following a procedure previously described by the authors (Gonçalves et al., 2017). Detection was carried out using a DAD $(520 \mathrm{~nm}$ as the preferred wavelength) and in a mass spectrometer (Linear Ion Trap LTQ XL mass spectrometer, Thermo Finnigan, San Jose, CA, USA) equipped with an ESI source, working in positive mode. The anthocyanin compounds were characterized according to their UV-Vis, mass spectra and their retention times, and compared with authentic standards. A total of three anthocyanin compounds were found and identified: delphinidin3-glucoside (C1), cyanidin-3-glucoside (C2) and cyanidin-3-pentoside (C3). For quantitative analysis, a 5-level calibration curve was obtained by injection of known concentrations $(50-0.25 \mu \mathrm{g} / \mathrm{mL})$ of cyaniding-3glucoside $\left(y=243287 x-1000000 ; R^{2}=0.9953\right.$, Polyphenols AS, Sandnes, Norway).

\subsection{Response format values for the results presentation}

Individual contents of three anthocyanin compounds (C1, C2 and C3) and total anthocyanins (CT) were defined as the responses to be quantified for each studied technique. The results were expressed in different format values: $Y_{1}$, content of anthocyanin per $g$ of dry weight material ( $\mu \mathrm{g} \mathrm{C} / \mathrm{g}$ fruit $\mathrm{dw}$ ), i.e. the anthocyanin extraction yield; and $Y_{2}$, the content of anthocyanin in the extract residue ( $\mu \mathrm{g} \mathrm{C} / \mathrm{g} \mathrm{R}$ ), which is used to evaluate anthocyanin purity in the extracts. Additionally, the extract yield of the residue obtained was quantified ( $\mathrm{g} / \mathrm{g}$ fruit $\mathrm{dw}$ ). 


\subsection{Experimental design, model analysis and statistical evaluation}

\subsubsection{RSM experimental design}

Trials based in one-at-the-time analysis of the each of the variables for each of the selected techniques were conducted. The variables that caused significant changes and the relevant ranges of action were selected for each one of the studied techniques (Table A1 at the supplemental material). The combined effect of these three variables were studied using a circumscribed central composite design (CCCD) using five levels for each one (Heleno et al., 2016) with twenty response combinations.

\subsubsection{Mathematical model}

The RSM data were fitted by means of least-squares calculation using the following second-order polynomial equation:

$Y=b_{0}+\sum_{i=1}^{n} b_{i} X_{i}+\sum_{\substack{i=1 \\ j>i}}^{n-1} \sum_{j=2}^{n} b_{i j} X_{i} X_{j}+\sum_{i=1}^{n} b_{i i} X_{i}^{2}$

where $Y$ is the dependent variable (response variable) to be modelled, $X_{i}$ and $X_{j}$ define the independent variables, $b_{o}$ is the constant coefficient, $b_{i}$ is the coefficient of linear effect, $b_{i j}$ is the coefficient of interaction effect, $b_{i i}$ the coefficients of quadratic effect and $n$ is the number of variables. As responses, the three format values, $Y_{1}, \mu \mathrm{g} \mathrm{C} / \mathrm{g}$ fruit dw; $Y_{2}$, $\mu \mathrm{g} \mathrm{C} / \mathrm{g} \mathrm{R}$; and yield, $\mathrm{g} \mathrm{R} / \mathrm{g}$ fruit $\mathrm{dw}$, were used.

\subsubsection{Procedure to optimize the variables to a maximum response}

A simplex method was used to optimize the predictive model by solving nonlinear problems in order to maximize the extraction yield and the recovery of phenolic compounds (Vieira et al., 2017). Certain limitations were imposed (i.e., times lower than 0) to avoid variables with unnatural and unrealistic physical conditions.

\subsection{Dose-response analysis of the solid to liquid ratio}

Once the optimal conditions $\left(X_{1}, X_{2}\right.$ and $\left.X_{3}\right)$ were found, the following natural optimization step was to describe the pattern of the solid/liquid ratio $\left(S / L\right.$ or $X_{4}$, expressed in $\left.\mathrm{g} / \mathrm{L}\right)$ aiming at achieving more productive processes as requested by industrial applications. To depict the response effect as function of the variation of the $S / L$ ratio the Weibull (W) equation (Prieto, Curran, Gowen, \& Vázquez, 2015), was used with some modifications to fit the purposes:

$W(S / L)=K\left\{1-\exp \left[-\ln 2(S / L / m)^{a}\right]\right\}$

where $K$ is the maximum extraction value (response criteria units, i.e. if $Y_{1}$ the units would be $\mu \mathrm{g} \mathrm{CT} / \mathrm{g}$ fruit dw), $m$ ( $S / L$ units, in this case $g$ fruit $\mathrm{dw} / \mathrm{L})$, the dose required for $50 \%$ of the maximum extraction value $(K)$ and $a$ shape parameter related to the maximum slope of the response. The rate of the process parameter $\left(v\right.$, i.e. if assessing the $Y_{1}$ response criterion the units would be $\mu \mathrm{g} \mathrm{C/g}$ fruit $\mathrm{dw}$ per $\mathrm{g}$ fruit $\mathrm{dw} / \mathrm{L}$ ) can be obtained by using the parametric values of Eq. (2) as follows:

$v=\frac{K \alpha}{m}(\ln 2)^{1 / a} G^{G} \exp (-G) ;$ where $G=\frac{\alpha-1}{\alpha}$

The parameter $v$ provides information related to the decreasing average value of the extraction as function of $S / L$ increasing. Therefore, the three parametric values of $K, m$ and $v$ can be used to assess the $S / L$ trends.

\subsection{Numerical methods, statistical analysis and graphical illustrations}

All fitting procedures, coefficient estimates and statistical calculations were performed using a Microsoft Excel spreadsheet. Fitting and statistical analysis of the experimental results according to the proposed equations were carried out in four phases:
- Coefficients determination: Parametric estimates were obtained by minimization of the sum of quadratic differences between observed and model-predicted values, using the nonlinear least-square (quasiNewton) method provided by the macro Solver in Microsoft Excel 2003 (Kemmer \& Keller, 2010), which allows a quick testing of a hypotheses and its consequences (Murado \& Prieto, 2013).

- Coefficients significance: The determination of the parametric confidence intervals was done using the "SolverAid" (Prikler, 2009). The model was simplified by dropping the terms that were not statistically significant for a $p$-value $(p)>0.05$ (data not displayed in tables).

- Model consistency: The Fisher F-test $(\alpha=0.05)$ was used to determine whether the constructed models were adequate to describe the observed data (Shi \& Tsai, 2002).

- Other statistical assessment criteria: To recheck the uniformity of the model, the following criteria were applied: a) The "SolverStat" macro was used for the assessment of parameter and model prediction uncertainties (Comuzzi, Polese, Melchior, Portanova, \& Tolazzi, 2003) b) The $\mathrm{R}^{2}$ was interpreted as the proportion of variability of the dependent variable explained by the model; $c$ ) The adjusted coefficient of determination $\left(R_{\text {adj }}^{2}\right.$ ) was a correction to $R^{2}$ taking into account the number of variables used in the model; $d$ ) Bias and accuracy factors of all equations were calculated to evaluate the quality of the fitting to the experimental data, such as the mean squared error (MSE), the root mean square error (RMSE) and the mean absolute percentage error (MAPE); e) The Durbin-Watson coefficient (DW) was used to check if the residuals of the model were not autocorrelated; and $\mathrm{f}$ ) The analysis of variance table (ANOVA) was used to evaluate the explanatory power of the variables(data not displayed in tables).

\section{Results and discussion}

3.1. Preliminary experiments to select the relevant variables and instrumental parameters to center experimental domains before the RSM application

The inherent characteristics of the natural matrices, the type of used solvents and the susceptibility of anthocyanin compounds to undergo degradation under certain ranges of temperature, time and $\mathrm{pH}$, difficult their extraction. The selection of an adequate extraction method, solvent type and optimal conditions to conduct the extraction have gained particular relevance (Casedas, Les, Gomez-Serranillos, Smith, \& Lopez, 2017; Chemat, Rombaut, Meullemiestre, et al., 2017; Khadhraoui et al., 2018; Wang \& Weller, 2006). In this regard, efforts have been made to develop and compare extraction processes having in view improved extraction yields (Silva, Costa, Calhau, Morais, \& Pintado, 2017). However, comparing results of different extraction techniques can be a hard task since variations from matrix to matrix hampers straightforward comparisons (Chemat, Rombaut, Meullemiestre, et al., 2017; Khadhraoui et al., 2018). Therefore, to provide a better understanding of the potential of different extraction techniques, in the present work, a study was conducted by selecting two relevant solid-liquid techniques for the extraction of anthocyanins that were further compared by using equivalent extraction conditions.

\subsubsection{Selection of the techniques for comparative analysis}

Heat assisted extraction (HAE) is the conventional solid-liquid extraction method to obtain anthocyanin compounds from plant matrices. The procedure consists in mixing the solid with a solvent followed by stirring for a certain period of time at a specific temperature. It is a simple technique with low requirements in terms of equipment, but very often involves long extraction times and requests high temperatures. Within the green technological advances, a broad spectrum of solid-liquid procedures is available for anthocyanin extraction. Some of these technologies include supercritical extraction, microwave-assisted 
extraction, ultrasound assisted extraction (UAE), and pressurized liquid extraction (Choi et al., 2011). As an alternative to the HAE, the UAE was selected as potential alternative, because it is one of the most effective techniques to extract phytochemical compounds. During ultrasound extraction, the rupture of plant cell walls occurs due to cavitation effects, thus increasing the contact area between the solid and the solvent (Pingret, Fabiano-Tixier, Bourvellec, Renard, \& Chemat, 2012). Some advantages related to the use of UAE technique have been reported, namely it is faster than conventional methodologies and energetically less demanding (Jacotet-Navarro et al., 2016). Moreover, it often leads to solvent consumption reduction and to the obtainment of extracts with higher purity levels (Wang \& Weller, 2006).

\subsubsection{Choice of the solvent for the anthocyanins extraction}

Solvent type and composition, in the case of mixtures, are key factors for the successful extraction of targeted compounds. The classic extraction solvents used to recover anthocyanins from plant tissues are water, polar solvents (e.g. methanol, ethanol or acetone) and aqueous organic solvent mixtures (Piñeiro, Palma, \& Barroso, 2004; Vuong, Golding, Nguyen, \& Roach, 2010). Acidified solvents are also suggested due to the instability of anthocyanins at $\mathrm{pH}>4$. The applied acid affects the extraction differently, but it seems to be consensual that citric acid, $\mathrm{HCl}$ and TFA, in combination with polar solvents, lead to the best mixtures to be used in the extraction of anthocyanins. Many authors apply solvent acidification and results from the literature survey showed that significantly higher amounts of anthocyanins are obtained if extractions are carried out with acidified solvent (Choung et al., 2001; Mojica, Berhow, \& Gonzalez de Mejia, 2017). Binary mixtures of ethanol with water (ethanol content ranging from 0 to 100\%) were selected as the extraction solvent. In all systems, acidification was performed $(0.05 \% \mathrm{HCl}, \mathrm{pH}=4)$.

\subsubsection{Choice of main variable conditions to apply with the selected techniques}

Several factors associated with chemical changes in the extraction process have been reported to affect the extraction yield. Although they are dependent on the employed technique, the most commonly variables reported in literature addresses the combination of $T$ and $t$ for HAE, and $P$ and $t$ for UAE. Thus, based in preliminary trials for HAE the following ranges were chosen: $t(30-150 \mathrm{~min})$ and $T\left(30-90^{\circ} \mathrm{C}\right)$, and for UAE: $t(3-45 \mathrm{~min})$ and $P(100-500 \mathrm{~W})$.

Additionally, several other factors related with the mass transfer effects, such as solid/liquid ratio, are repeatedly mentioned (Silva et al., 2017). A broad range of $S / L$ ratios were tested, finding that lower values lead to an enhanced extraction yield and higher $S / L$ will result in lower extraction yields. Although the differences were significant, this variable was initially discarded in the RSM optimization, and the value of $30 \mathrm{~g} / \mathrm{L}$ was selected to be used in both tested extraction techniques.

In brief, the efficiency of HAE and UAE processes for anthocyanins (AC) extraction from $A$. unedo fruits was evaluated by RSM using three variables ( $t, T$ and $S$ for HAE and $t, P$ and $S$ for UAE) in a CCCD with five level values per variable. This multivariable fitting provides a strong solution that minimizes the experimental errors with a short number of trials, while optimizing the variable conditions assisted by empirical mathematical models, which predict the maximum extraction yield. Once the optimal conditions of the variables subjected to RSM analysis were optimized, the pattern of the solid/liquid ratio $(S / L$ expressed in $\mathrm{g} / \mathrm{L}$ ) was optimized ( 5 to $200 \mathrm{~g} / \mathrm{L}$ ). A comprehensive summary of the different steps carried out is presented in Fig. A1 (supplementary material).

\subsection{Optimization of the RSM analysis using the 3 variables}

3.2.1. Mathematical models derived from the RSM for a CCCD with the three defined variables and statistical assessment

Before assessing the optimization process, the compounds present in the samples had to be characterized. The anthocyanin compounds profile of strawberry-tree fruits obtained by HPLC-DAD-ESI/MS analysis consisted of three anthocyanins, delphinidin-3-glucoside (C1), cyanidin-3-glucoside (C2) and cyanidin-3-pentoside (C3), being cyanidin-3-glucoside the most abundant one, as previously reported by the authors (Guimarães et al., 2013). Other authors conducted studies reporting the six most common anthocyanins in nature and cyanidin was identified as the most abundant compound in all the studied berry fruits (blueberry, blackberry, cranberry, black grape, raspberry and strawberry), and therefore used as the reference for anthocyanins.

The results obtained by the statistical CCCD are shown in Table 1 for the studied extraction techniques (HAE and UAE). By fitting the secondorder polynomial model of Eq. (1) to the obtained responses using nonlinear least-squares estimations, the parametric values were obtained and presented in Table 2. Those coefficients, which showed confidence interval values ( $\alpha=0.05)$ higher than the parameter value, were consider as non-significant (ns) and were not used for the model development. Table A2 (supplementary material) shows the resulting models (Eqs. (4)-(21), supplemental material) for each one of the assessed response criteria ( $Y_{1}$ in $\mu \mathrm{g} \mathrm{C} / \mathrm{g}$ fruit dw, $Y_{2}$ in $\mu \mathrm{g} \mathrm{C} / \mathrm{g} \mathrm{R}$ and yield $\%$ ), in terms of the individually identified anthocyanins (C1, C2 and C2) and their total amount (CT) for each one of the studied techniques (HAE and UAE). Eqs. (4)-(21) translate the response patterns for the two response criteria formats $\left(Y_{1}\right.$ and $\left.Y_{2}\right)$ and the extraction yield $(\mathrm{g} R / \mathrm{g}$ fruit $\mathrm{dw}$ ), showing a relatively high complexity of sceneries.

In statistical terms, the used tests to assess the competence of the models showed that the non-significant parameters of both RSM approaches (Table 2) did not improve the reached solution and; in contrast, all significant parameters were highly consistent $(\mathrm{p}<0.01$ ). This was also verified by the achieved high $\mathrm{R}^{2}$ and $\mathrm{R}_{\text {adj }}^{2}$ values, indicating the percentage of variability explained by the model. The statistic lack of fit (MSE, RMSE, MAPE, DW) used to test the adequacy of the developed models demonstrated that non-considerable improvement was achieved by the inclusion of the statistically non-significant ( $n s)$ parameters (Table 2).

Additionally, the agreement between the experimental and predicted values implies an acceptable explanation of the results obtained by the used independent variables. Therefore, the models developed in Eqs. (4)-(21) are completely functional and adequate to be used for prediction and process optimization.

\subsubsection{Response patterns derived from the RSM}

The parametric values presented in Table 2 derived from the RSM models give us a relevant global information of the responses, but also of the suitability of the used method. In one hand, the linear and quadratic effects are found to play an important and significant role in all cases (each response criteria assessed in HAE and UAE techniques). The presence of linear and quadratic effects implies that almost all responses showed non-linear patterns, which are related with the nature of the chosen variables in HAE and UAE. On the other hand, the interactive parametric values can act as control values for the RSM analysis providing comprehension of the assessed variables. In fact, if they are present in the derived mathematical models, it indicates that if responses are studied separately, instead of using a multivariable analysis (such as RSM), the definition of the proper optimum conditions is not possible, and therefore the maximum extraction yield conditions will never be properly achieved. Regarding the interactive effects found in the performed analyses (Table 2), the HAE displayed representative effects in almost all the possible response interactions ( $t T, t S$ and $T S$ ) with strong impact on $t S$. For the UAE, no response interactions were found for $t P$, two significant interactions were found for $P S$, and for almost all cases positive interactions between $t S$ were observed. In conclusion, a non-linear multivariable analysis was needed in order to fully fit the experimental results. Additionally, the variables assessed in HAE showed clear interactions, whereas for UAE only the interactive effect of $t S$ were relevant. 
Table 1

Experimental RSM results of the CCCD for the optimization of the three main variables involved $\left(X_{1}, X_{2}\right.$ and $\left.X_{3}\right)$ in the HAE and UAE for the three response value formats assessed ( $Y_{1}, \mu \mathrm{g} \mathrm{C} / \mathrm{g}$ fruit dw; $Y_{2}, \mu \mathrm{g} \mathrm{C} / \mathrm{g}$ R; and Yield,\%). Variables, natural values and ranges in Table A1.

\begin{tabular}{|c|c|c|c|c|c|c|c|c|c|c|c|c|c|c|c|c|c|c|c|c|}
\hline \multirow[t]{4}{*}{ Variable } & \multicolumn{2}{|c|}{ Coded Values } & \multicolumn{18}{|c|}{ Experimental responses } \\
\hline & & & \multicolumn{9}{|c|}{ Heat assisted extraction (HAE) } & \multicolumn{9}{|c|}{ Ultrasound assisted extraction (UAE) } \\
\hline & & & \multirow[t]{2}{*}{ Yield } & \multicolumn{2}{|l|}{$\mathrm{C} 1$} & \multicolumn{2}{|l|}{$\mathrm{C} 2$} & \multicolumn{2}{|l|}{ C3 } & \multicolumn{2}{|l|}{ CT } & \multirow[t]{2}{*}{ Yield } & \multicolumn{2}{|l|}{$\mathrm{C} 1$} & \multicolumn{2}{|l|}{$\mathrm{C} 2$} & \multicolumn{2}{|l|}{$\mathrm{C} 3$} & \multicolumn{2}{|l|}{$\mathrm{CT}$} \\
\hline & & & & $Y_{1}$ & $Y_{2}$ & $Y_{1}$ & $Y_{2}$ & $Y_{1}$ & $Y_{2}$ & $Y_{1}$ & $Y_{2}$ & & $Y_{1}$ & $Y_{2}$ & $Y_{1}$ & $Y_{2}$ & $Y_{1}$ & $Y_{2}$ & $Y_{1}$ & $Y_{2}$ \\
\hline-1 & -1 & -1 & 70.0 & 38.3 & 54.7 & 176.8 & 252.8 & 47.2 & 67.5 & 262.3 & 374.9 & 71.1 & 33.5 & 47.2 & 105.3 & 168.1 & 37.6 & 60.0 & 176.4 & 281.7 \\
\hline 1 & -1 & -1 & 67.5 & 37.4 & 55.5 & 170.7 & 253.0 & 45.9 & 68.0 & 254.1 & 376.5 & 81.0 & 32.0 & 39.5 & 71.9 & 100.9 & 33.4 & 46.9 & 137.3 & 192.7 \\
\hline-1 & 1 & -1 & 69.0 & 38.5 & 55.8 & 198.3 & 287.4 & 50.2 & 72.7 & 287.0 & 415.9 & 77.8 & 32.1 & 41.2 & 80.4 & 117.4 & 34.3 & 50.1 & 146.8 & 214.3 \\
\hline 1 & 1 & -1 & 65.5 & 31.3 & 47.7 & 56.8 & 86.7 & 34.4 & 52.5 & 122.5 & 186.8 & 97.5 & 31.1 & 31.9 & 54.7 & 63.8 & 31.7 & 37.0 & 117.5 & 137.0 \\
\hline-1 & -1 & 1 & 60.6 & 36.8 & 60.7 & 137.1 & 226.3 & 43.2 & 71.4 & 217.1 & 358.3 & 65.4 & 38.7 & 59.1 & 177.6 & 308.5 & 47.8 & 83.0 & 264.1 & 458.7 \\
\hline 1 & -1 & 1 & 70.5 & 40.5 & 57.4 & 183.6 & 260.5 & 48.7 & 69.2 & 272.8 & 387.1 & 74.7 & 37.9 & 50.7 & 176.2 & 268.1 & 46.8 & 71.2 & 260.9 & 396.9 \\
\hline-1 & 1 & 1 & 65.3 & 38.8 & 59.5 & 220.6 & 337.6 & 51.4 & 78.6 & 310.8 & 475.7 & 74.2 & 38.5 & 51.9 & 172.8 & 264.6 & 46.9 & 71.9 & 258.3 & 395.5 \\
\hline 1 & 1 & 1 & 74.5 & 34.6 & 46.4 & 133.5 & 179.2 & 40.9 & 54.9 & 209.1 & 280.5 & 79.0 & 38.6 & 48.8 & 181.1 & 260.5 & 47.2 & 67.9 & 266.9 & 383.9 \\
\hline-1.68 & 0 & 0 & 67.3 & 37.4 & 55.6 & 174.3 & 258.8 & 47.8 & 71.0 & 259.6 & 385.4 & 72.4 & 38.6 & 53.4 & 190.9 & 299.7 & 48.0 & 75.4 & 277.5 & 435.8 \\
\hline 1.68 & 0 & 0 & 73.1 & 34.9 & 47.8 & 131.7 & 180.2 & 41.9 & 57.3 & 208.5 & 285.4 & 93.6 & 36.3 & 38.8 & 154.6 & 187.6 & 43.7 & 53.0 & 234.6 & 284.6 \\
\hline 0 & -1.68 & 0 & 70.6 & 37.5 & 53.1 & 181.4 & 257.0 & 47.6 & 67.5 & 266.5 & 377.6 & 69.0 & 37.0 & 53.5 & 155.7 & 256.4 & 43.5 & 71.6 & 236.2 & 388.8 \\
\hline 0 & 1.68 & 0 & 73.1 & 34.7 & 47.5 & 150.9 & 206.2 & 43.6 & 59.6 & 229.2 & 313.4 & 73.9 & 36.1 & 48.9 & 133.3 & 205.0 & 42.5 & 65.4 & 211.9 & 325.9 \\
\hline 0 & 0 & -1.68 & 64.0 & 35.7 & 55.7 & 128.5 & 200.6 & 40.7 & 63.6 & 204.9 & 319.9 & 86.5 & 34.0 & 39.3 & 102.2 & 134.3 & 38.0 & 49.9 & 174.3 & 228.9 \\
\hline 0 & 0 & 1.68 & 65.2 & 38.9 & 59.7 & 184.0 & 282.4 & 47.9 & 73.5 & 270.7 & 415.5 & 58.7 & 34.6 & 59.0 & 95.9 & 185.7 & 36.7 & 71.1 & 167.2 & 323.8 \\
\hline 0 & 0 & 0 & 74.1 & 38.7 & 52.2 & 200.7 & 271.0 & 49.5 & 66.8 & 288.9 & 390.1 & 83.6 & 41.7 & 49.9 & 228.2 & 310.1 & 54.5 & 74.1 & 324.4 & 440.9 \\
\hline 0 & 0 & 0 & 74.5 & 39.2 & 52.6 & 202.7 & 272.2 & 50.5 & 67.7 & 292.4 & 392.6 & 82.8 & 42.1 & 50.8 & 223.9 & 307.2 & 53.4 & 73.3 & 319.4 & 438.2 \\
\hline 0 & 0 & 0 & 74.6 & 38.7 & 51.8 & 203.7 & 273.0 & 50.4 & 67.5 & 292.7 & 392.3 & 82.6 & 41.4 & 50.1 & 242.4 & 333.3 & 54.0 & 74.3 & 337.8 & 464.5 \\
\hline 0 & 0 & 0 & 73.8 & 39.2 & 53.1 & 203.5 & 275.7 & 50.0 & 67.7 & 292.7 & 396.4 & 83.8 & 41.1 & 49.1 & 237.4 & 321.9 & 58.3 & 79.1 & 336.9 & 456.8 \\
\hline 0 & 0 & 0 & 73.8 & 38.3 & 51.9 & 202.3 & 274.0 & 50.4 & 68.3 & 291.0 & 394.2 & 82.4 & 42.2 & 51.3 & 237.7 & 327.8 & 55.4 & 76.5 & 335.4 & 462.5 \\
\hline 0 & 0 & 0 & 74.4 & 38.4 & 51.6 & 205.6 & 276.3 & 50.4 & 67.7 & 294.4 & 395.7 & 83.8 & 41.7 & 49.7 & 228.0 & 309.1 & 53.5 & 72.5 & 323.2 & 438.1 \\
\hline
\end{tabular}

Three replicates were performed for each condition for each technique. Three replicates were performed for each condition for each technique for each response. None of the SD of the results showed a higher deviation value than $5 \%$ of the results produced.

Fig. 1 shows the results of HAE and UAE for the extraction yield and the results obtained for $\mathrm{CT}$ in the two response format values $\left(Y_{1}\right.$ and $Y_{2}$ ). Each figure is divided in two zones, each one showing the results obtained with each tested technique. Additionally, each zone is divided into two sections (A and B). Section A shows the 3D surface plots for the three possible variable combinations produced by Eqs. (4)-(21). The binary action between variables is presented when the excluded one is located at the optimum individual value predicted (part A of Table 3). Subsection B illustrates the capability to predict the obtained results and the residual distribution as a function of each one of the considered variables. Taking the distribution of the residuals presented in Fig. 1 as example of all the achieved responses, it can be perceived that they are arbitrarily around zero and no groups of values, or autocorrelations, were observed.

Fig. 2 and Fig. A2 (supplementary material) show the optimized responses in contour graphs $\left(Y_{1}, Y_{2}\right.$ and yield) for each of the identified anthocyanins (C1, C2 and C3) as a function of the three main variables involved in HAE and UAE, respectively. The isolines represent the projection in XY plane of the theoretical three-dimensional response surface predicted with the second order polynomial of Eq. (1) by the binary actions between two variables when the excluded variable is positioned at the predicted optimum individual value (part A of Table 3). In Fig. 2 and Fig. A2 (supplementary material), the extract yield response is repetitively displayed to better understand the changes produced in the $Y_{1}$ and $Y_{2}$ responses.

Fig. 3 part $\mathrm{A}$, shows the summarized individual $2 \mathrm{D}$ responses as a function of the defined variables for HAE and UAE extraction techniques, to guide the selection of the most favorable conditions. The line represents the variable response pattern when the others are located at the optimal values presented in the third part of Table 3. The dots $(\odot)$ presented alongside the line highlight the location of the optimal value. The properly optimized responses display patterns in which the amount of extracted compounds increases to an optimum value and then decreases as a function of each of the assessed independent variables. Therefore, an absolute optimum can be found at one single point, allowing computing the conditions that lead to the absolute maximum. This type of responses can be easily depicted in the 3D representations of the responses presented in Fig. 1, Fig. 2 and Fig. A2. For instance, nearly all responses derived from the UAE produced clear absolute optimal responses for all variables, whereas less conclusive solutions were found for HAE, although tendencies towards an absolute optimum are visually observed.

\subsubsection{Individual and global numerical optimal conditions that maximize the extraction}

The optimal absolute or relative (marked with $*$ ) conditions that maximize the individual and global responses criteria of the responses presented in Fig. 1, Fig. 2 and Fig. A2 are displayed numerically in Table 3 and graphically in Fig. 3 part A. These values were obtained by a simplex procedure inserting restrictions to the experimental ranges.

In this regard, part A of Table 3 shows the individual conditions for HAE and UAE of the responses criteria $Y_{1}$ and $Y_{2}$ for each identified individual anthocyanin (C1, C2 and C3) and their total amount (CT). The most abundant anthocyanin compound was C2 (cyanidin-3-glucoside) either as $Y_{1}\left(\sim 240 \mu \mathrm{g} \mathrm{C} 2 / \mathrm{g}\right.$ fruit dw by UAE) or $Y_{2}(\sim 400 \mu \mathrm{g} \mathrm{C} 2 / \mathrm{g}$ $\mathrm{R}$ by HAE) response format values, followed by $\mathrm{C} 3$ (cyanidin-3-pentoside) and C1 (delphinidin-3-glucoside). The highest extraction of total anthocyanins (CT) was obtained by the HAE producing values of $330.8 \pm 17.6 \mu \mathrm{g} \mathrm{C} / \mathrm{g}$ fruit $\mathrm{dw}$ obtained at $* 20.0 \mathrm{~min}, * 90.0{ }^{\circ} \mathrm{C}$ and ethanol content of $63.5 \%$ (response format value of $Y_{1}$ ) and $551.6 \pm 24.3 \mu \mathrm{g} \mathrm{C} / \mathrm{g} \mathrm{R}$ obtained at $* 20.0 \mathrm{~min}, * 90.0^{\circ} \mathrm{C}$ and ethanol content of $* 100 \%$ (response format value of $Y_{2}$ ). The responses achieved by UAE were close to those produced by HAE, presenting values of $338.7 \pm 23.7 \mu \mathrm{g} \mathrm{C} / \mathrm{g}$ fruit $\mathrm{dw}\left(Y_{1}\right.$, at $27.6 \mathrm{~min}, 241.0 \mathrm{~W}$ and ethanol content of $59.7 \%)$ and $487.0 \pm 28.4 \mu \mathrm{g} \mathrm{C} / \mathrm{g} \mathrm{R}\left(Y_{1}\right.$, at $21.8 \mathrm{~min}$, $215.1 \mathrm{~W}$ and ethanol content of $64.3 \%$ ) . In addition, part A of Table 3 shows the extraction yield that was $75.3 \pm 3.9 \%$ per total fruit $\mathrm{dw}$ for HAE (101.9 min, $64.1{ }^{\circ} \mathrm{C}$ and ethanol content of $64.7 \%$ ) and $85.4 \pm 12.9 \%$ of the total fruit $\mathrm{dw}(55.0 \mathrm{~min}, 312.7 \mathrm{~W}$ and ethanol content of $4.5 \%$ ) for UAE. 


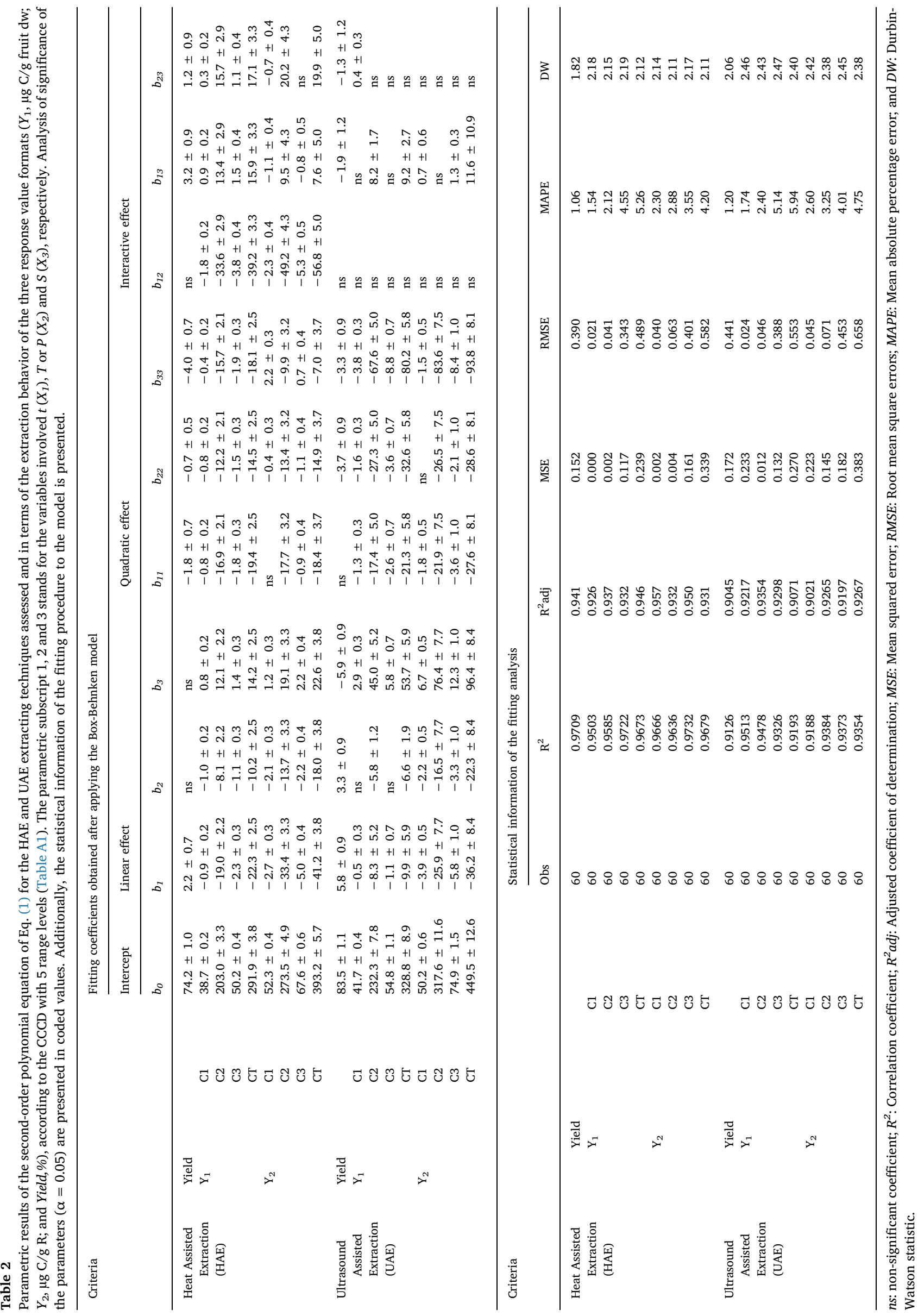




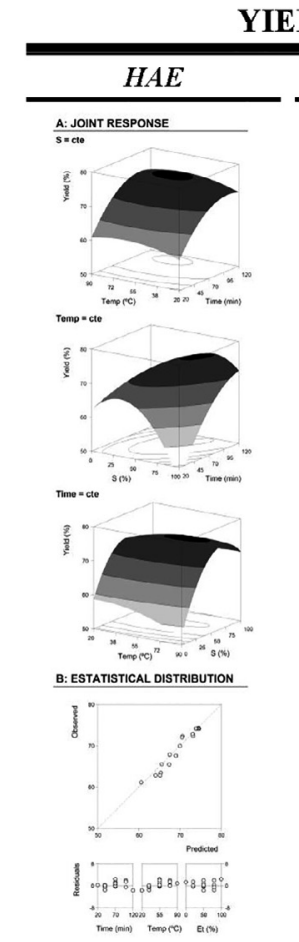

YIELD

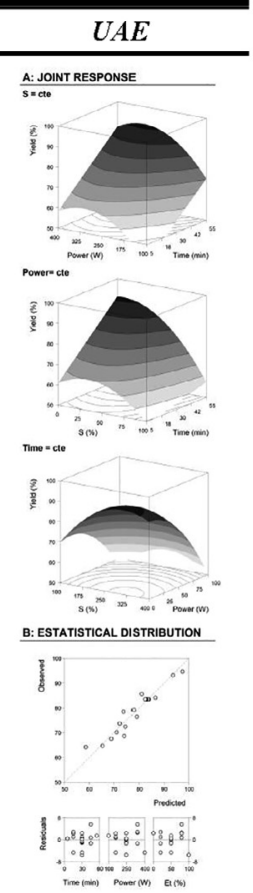

FRUIT

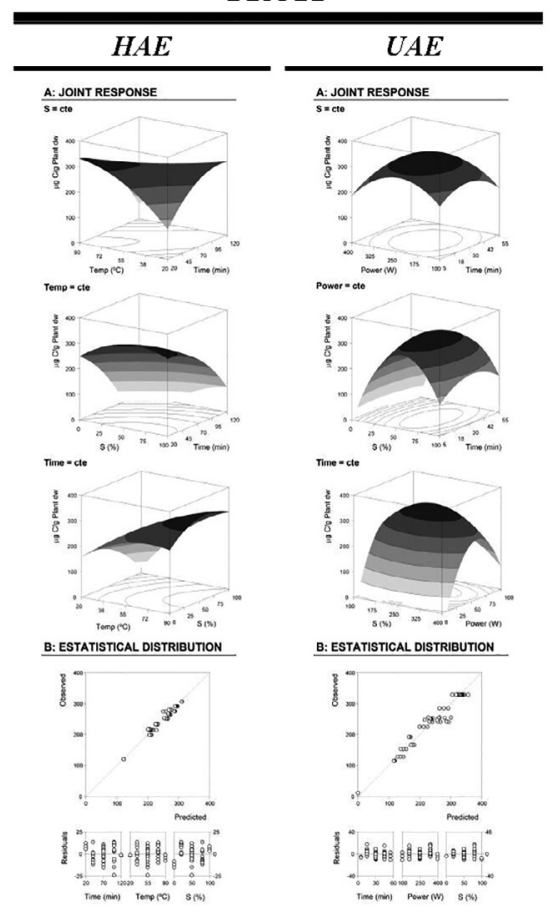

RESIDUE

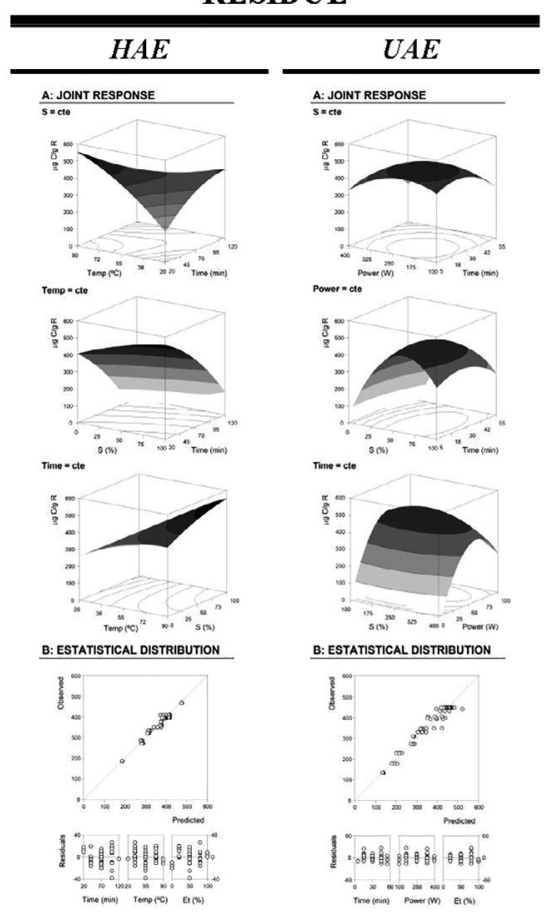

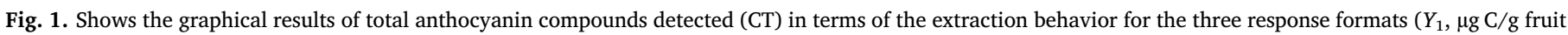

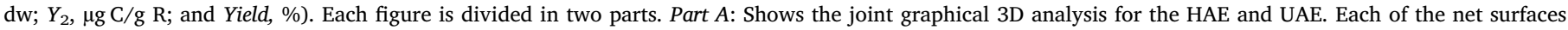

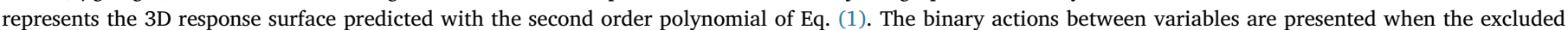

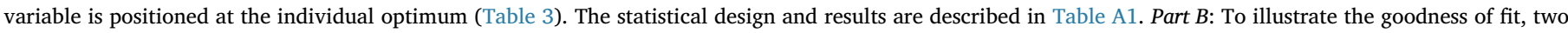

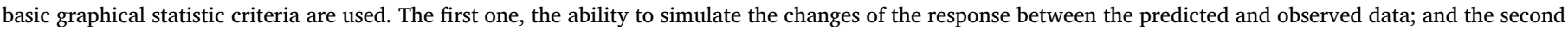
one, the residual distribution as a function of each of the variables.

Combining the information produced by the three responses criteria ( $Y_{1}, Y_{2}$ and extract yield), the complete behavior of each relevant variable influencing the responses is defined in global terms. The global optimizing results are presented in Table 3 part B and are summarized below:

- For HAE: the optimal global conditions were at $* 20.0 \mathrm{~min}, * 90.0^{\circ} \mathrm{C}$ and ethanol content of $63.5 \%$, producing an extract yield of $62.8 \pm 6.6 \%$ per total fruit $\mathrm{dw}$, and anthocyanins recovering of: $39.1 \pm 4.5 \mu \mathrm{g} \mathrm{C} 1 / \mathrm{g}$ fruit $\mathrm{dw}, 236.5 \pm 25.1 \mu \mathrm{g} \mathrm{C} 2 / \mathrm{g}$ fruit $\mathrm{dw}$, $54.0 \pm 6.1 \mu \mathrm{g} \mathrm{C} 3 / \mathrm{g}$ fruit $\mathrm{dw}$, and $329.5 \pm 34.7 \mu \mathrm{g} \mathrm{CT} / \mathrm{g}$ fruit $\mathrm{dw}$, according to $Y 1$ format; and $59.2 \pm 6.2 \mu \mathrm{g} \mathrm{C1} / \mathrm{g} \mathrm{R}$, $364.5 \pm 38.2 \mu \mathrm{gC} 2 / \mathrm{g} \quad \mathrm{R}, \quad 82.2 \pm 8.3 \mu \mathrm{g} \mathrm{C} 3 / \mathrm{g} \quad \mathrm{R}, \quad$ and $506.3 \pm 52.9 \mu \mathrm{g} \mathrm{CT} / \mathrm{g} \mathrm{R}$, according to $Y 2$ format.

- For UAE: the optimal global conditions were at $27.6 \mathrm{~min}, 243.7 \mathrm{~W}$ and ethanol content of $59.9 \%$, producing an extract yield of $79.97 \pm 9.2 \%$ per total fruit $\mathrm{dw}$, and anthocyanins recovering of: $42.2 \pm 5.7 \mu \mathrm{g} \mathrm{C} 1 / \mathrm{g}$ fruit $\mathrm{dw}, 240.6 \pm 26.1 \mu \mathrm{gC} 2 / \mathrm{g}$ fruit $\mathrm{dw}$, $55.8 \pm 6.3 \mu \mathrm{g} \mathrm{C} 3 / \mathrm{g}$ fruit $\mathrm{dw}$, and $338.6 \pm 36.2 \mu \mathrm{g} \mathrm{CT} / \mathrm{g}$ fruit $\mathrm{dw}$, according to $Y 1$ format; and $53.1 \pm 5.5 \mu \mathrm{g} \mathrm{C1} / \mathrm{g} \quad \mathrm{R}$, $338.7 \pm 36.8 \mu \mathrm{g} \mathrm{C} 2 / \mathrm{g} \quad \mathrm{R}, \quad 79.2 \pm 8.9 \mu \mathrm{g} \mathrm{C} 3 / \mathrm{g} \quad \mathrm{R} \quad$ and $477.6 \pm 50.5 \mu \mathrm{g} \mathrm{CT} / \mathrm{g}$ R, according to $Y 2$ format.

For both techniques, the conditions that lead to the optimal values were experimentally re-tested to ensure the accuracy of the presented results and slightly increased efficient responses, using HAE, were found. Due to the nature of the applied energy, the UAE seems to be the technique that should extract higher amounts of anthocyanins, but the results show the contrary (Khadhraoui et al., 2018). These results are corroborated in similar studies in which fruit material from the pulp of Vitis vinifera L. extracted by UAE produces values of $\sim 6350 \mu \mathrm{g} / \mathrm{g}$ of fruit $\mathrm{dw}$ and using HAE the achieved values were up to $\sim 17000 \mu \mathrm{g} / \mathrm{g}$ of fruit dw (Elisia, Hu, Popovich, \& Kitts, 2006). The high temperature used by HAE over the high penetration depth reached by UAE reduces dramatically both the extraction time and solvent consumption. However, the efficiency of UAE can be very poor when either the target compounds or the solvents are non-polar, or when they are volatile. Furthermore, many nutraceuticals are unstable and may degrade during extraction (Jacotet-Navarro et al., 2016; Wang \& Weller, 2006).

Regarding the used solvent, data in literature shows that in the majority of the cases, hydro-alcoholic mixtures conducted to higher amounts than pure alcohol or pure water, as shown in two studies describing the extraction of anthocyanins from the calyx of Hibiscus sabdariffa L., in which $\sim 200 \mu \mathrm{g} / \mathrm{g}$ of plant dw were obtained when pure water or pure alcohol were used, while $\sim 1250 \mu \mathrm{g} / \mathrm{g}$ of plant $\mathrm{dw}$ were obtained when 50:50 hydro-alcoholic mixtures were used (SalazarGonzález, Vergara-Balderas, Ortega-Regules, \& Beltrán, 2012). In the present work hydro-ethanolic mixtures worked better than the pure solvents itself as is corroborated by the values of achieved, mixtures with ethanol contents of $63.5 \%$ and $59.9 \%$ to the optimal solutions, respectively for HAE and UAE.

\subsubsection{Complementary kinetic study to find absolute maximum responses for the HAE}

Anthocyanins are known for their sensitivity to heat and, therefore, the extraction time is a particularly important variable, but it is highly dependent on the matrix used. The ultrasound frequencies are capable of facilitating the hydration of plant materials which leads to the enlargement of cell wall pores causing the rupture of the cell-wall, which accelerates the extraction process of compounds. At the same time, the cavitation phenomena creates currents and disruptive forces increasing the temperature of the solvent, that in cooled reactors as the one applied, may reach up to $70^{\circ} \mathrm{C}$, factor that may compromise anthocyanins stability if the $t$ needed is high (Castañeda-Ovando et al., 2009).

Comparing the results of extraction efficiencies among the techniques, HAE gave significantly higher values, while UAE extraction 

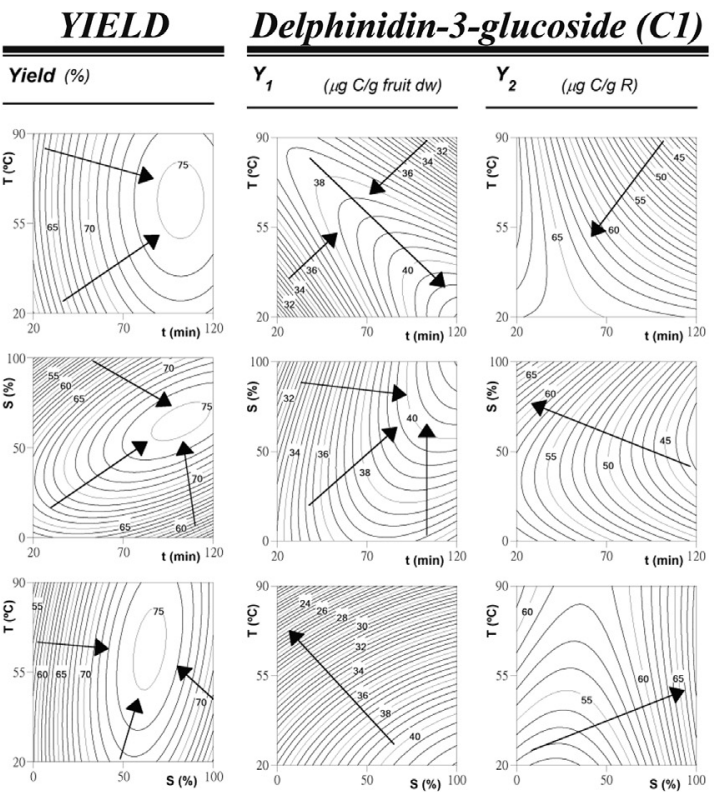

Cyanidin-3-glucoside (C2)
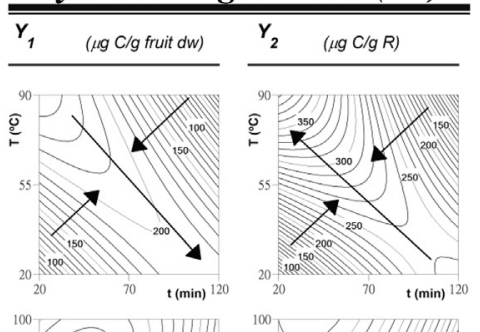

\section{Cyanidin-3-pentoside (C3)}
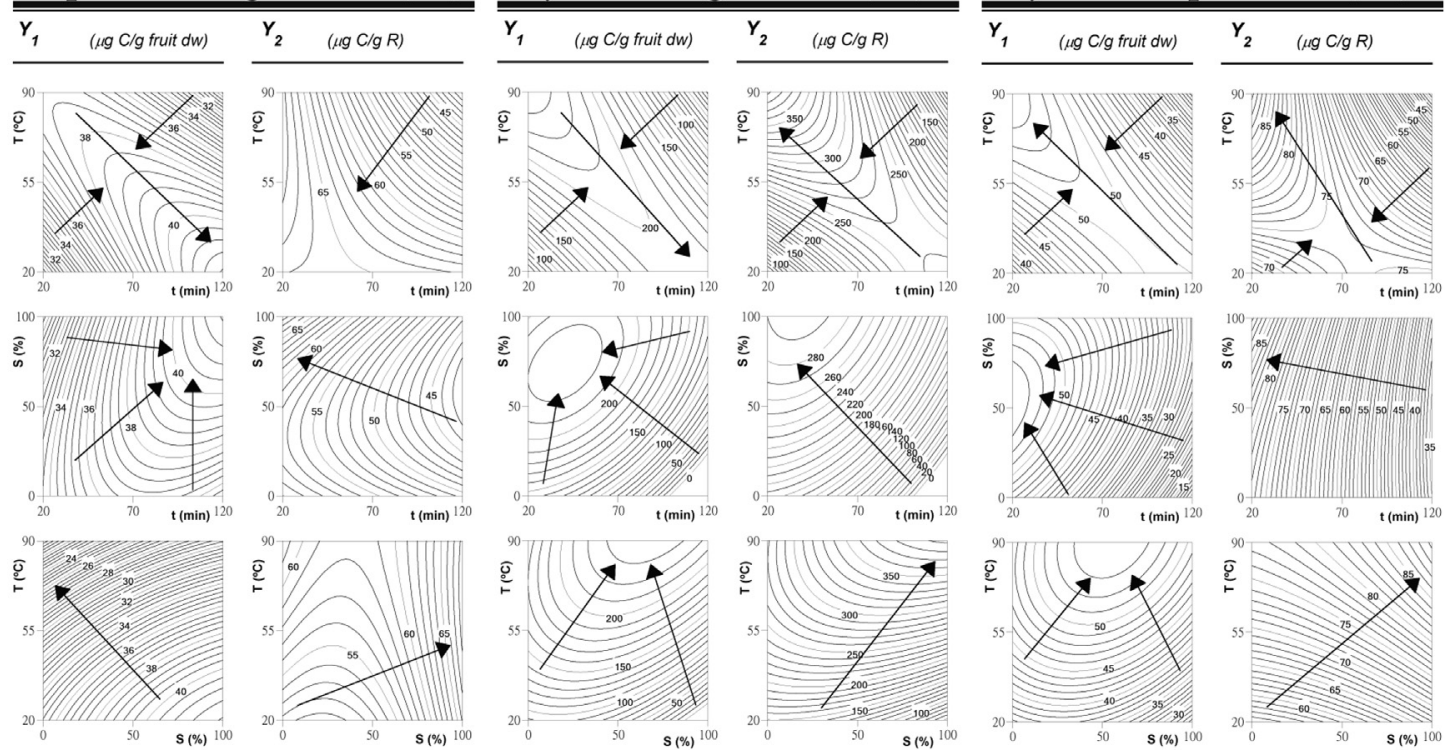

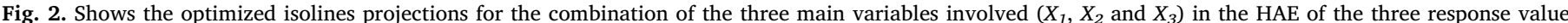

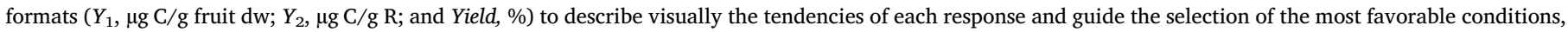

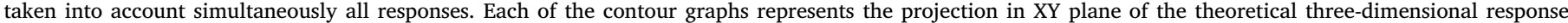

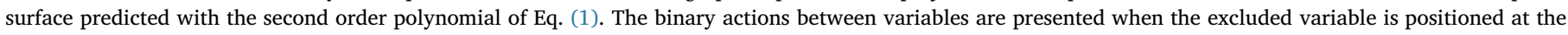
individual optimum (Table 3). The statistical design and experimental results are described in Table A1. Estimated parametric values are shown in Table 2.

\section{A: Optimized RSM variables}

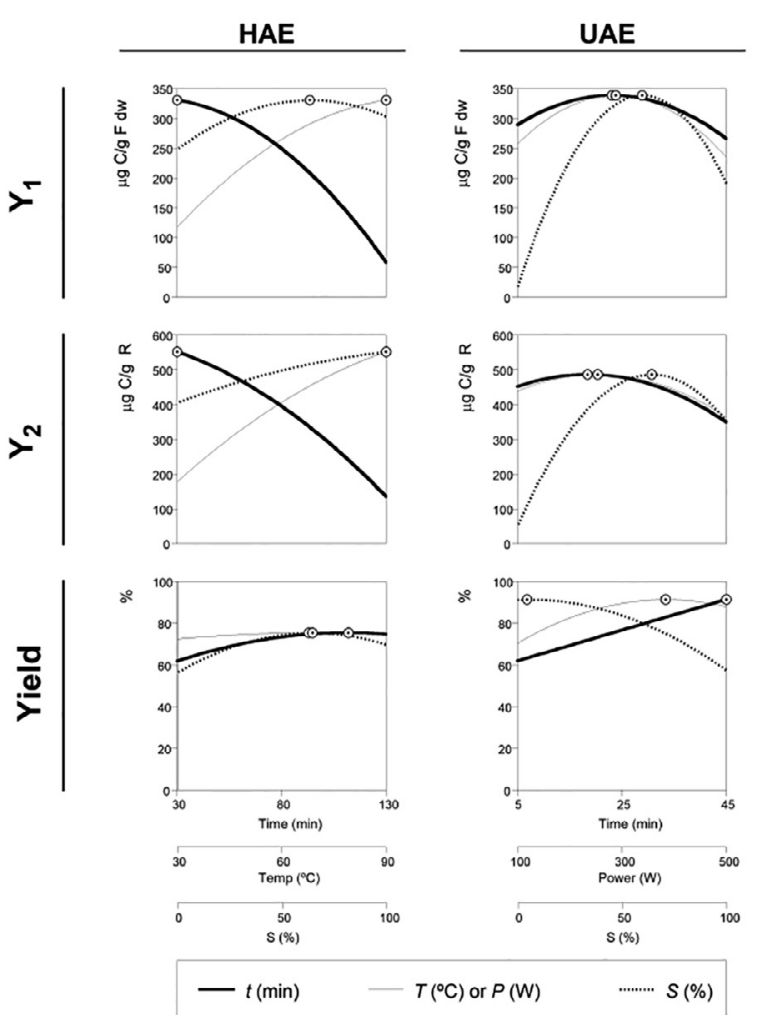

\section{B: Solid-to-liquid ratio patterns}
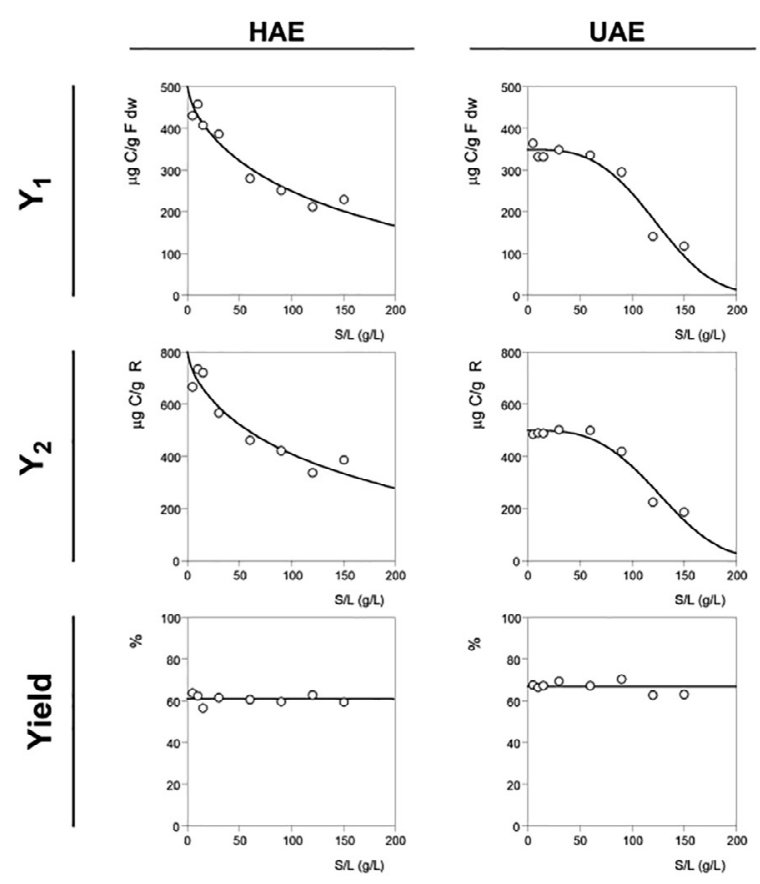

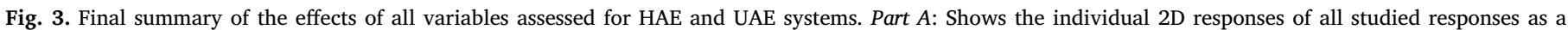

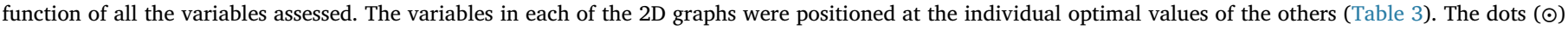

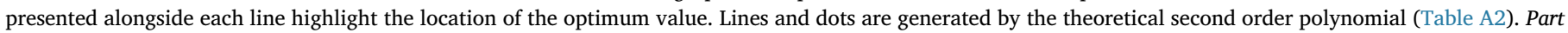

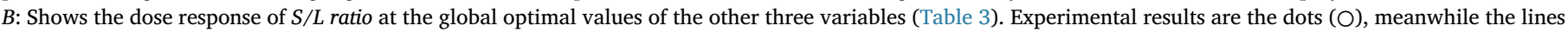

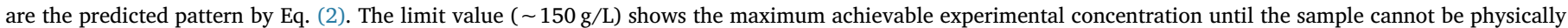
stirred at laboratory scale. 
Table 3

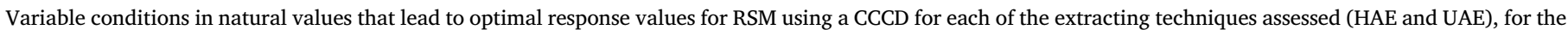
three response value formats $\left(Y_{1}, \mu \mathrm{g} \mathrm{C} / \mathrm{g}\right.$ fruit dw; $Y_{2}, \mu \mathrm{g} \mathrm{C} / \mathrm{g} \mathrm{R}$; and Yield,\%) for each compound assessed.

\begin{tabular}{|c|c|c|c|c|c|c|}
\hline \multirow[t]{2}{*}{ Criteria } & & \multicolumn{3}{|c|}{ Optimal variable Conditions } & \multicolumn{2}{|c|}{ Optimum response } \\
\hline & & $X_{1}: t(\min )$ & $X_{2}: T\left({ }^{\circ} C\right)$ or $P(W)$ & $X_{3}: S(\%)$ & & \\
\hline \multicolumn{7}{|l|}{ A) Individual optimal variable conditions } \\
\hline \multirow[t]{9}{*}{ Heat Assisted Extraction (HAE) } & Yield & & 101.9 & 64.1 & 64.7 & $75.3 \pm 3.9 \%$ \\
\hline & $Y_{1}$ & $\mathrm{C} 1$ & $120.0^{*}$ & $20.0^{*}$ & $100.0^{*}$ & $41.7 \pm 6.2 \mu \mathrm{g} \mathrm{C} 1 / \mathrm{g}$ fruit $\mathrm{dw}$ \\
\hline & & $\mathrm{C} 2$ & $20.0^{*}$ & $90.0^{*}$ & 65.2 & $238.2 \pm 14.9 \mu \mathrm{g} \mathrm{C} 2 / \mathrm{g}$ fruit $\mathrm{dw}$ \\
\hline & & $\mathrm{C} 3$ & $20.0^{*}$ & $90.0^{*}$ & 55.1 & $54.0 \pm 7.1 \mu \mathrm{g} \mathrm{C} 3 / \mathrm{g}$ fruit $\mathrm{dw}$ \\
\hline & & $\mathrm{CT}$ & $20.0^{*}$ & $90.0 *$ & 63.5 & $330.8 \pm 17.6 \mu \mathrm{g} \mathrm{CT} / \mathrm{g}$ fruit $\mathrm{dw}$ \\
\hline & $\mathrm{Y}_{2}$ & $\mathrm{C} 1$ & $20.0 *$ & 72.9 & $100.0^{*}$ & $68.6 \pm 3.1 \mu \mathrm{g} \mathrm{C} 1 / \mathrm{g} \mathrm{R}$ \\
\hline & & $\mathrm{C} 2$ & $20.0^{*}$ & $90.0^{*}$ & $100.0^{*}$ & $392.5 \pm 19.1 \mu \mathrm{g} \mathrm{C} 2 / \mathrm{g} \mathrm{R}$ \\
\hline & & $\mathrm{C} 3$ & $20.0^{*}$ & $90.0^{*}$ & $100.0^{*}$ & $89.3 \pm 1.3 \mu \mathrm{g} \mathrm{C} 3 / \mathrm{g} \mathrm{R}$ \\
\hline & & CT & $20.0^{*}$ & $90.0^{*}$ & $100.0^{*}$ & $551.6 \pm 24.3 \mu \mathrm{g} \mathrm{CT} / \mathrm{g} \mathrm{R}$ \\
\hline \multirow[t]{9}{*}{ Ultrasound Assisted Extraction (UAE) } & Yield & & 55.0 & 312.7 & 4.5 & $85.4 \pm 12.9 \%$ \\
\hline & $\mathrm{Y}_{1}$ & $\mathrm{C} 1$ & 26.9 & 253.8 & 61.3 & $42.3 \pm 14.4 \mu \mathrm{g} \mathrm{C} 1 / \mathrm{g}$ fruit $\mathrm{dw}$ \\
\hline & & $\mathrm{C} 2$ & 27.6 & 240.5 & 59.6 & $240.6 \pm 19.9 \mu \mathrm{g} \mathrm{C} 2 / \mathrm{g}$ fruit $\mathrm{dw}$ \\
\hline & & C3 & 27.0 & 250.0 & 59.8 & $55.9 \pm 6.8 \mu \mathrm{g} \mathrm{C} 3 / \mathrm{g}$ fruit $\mathrm{dw}$ \\
\hline & & $\mathrm{CT}$ & 27.6 & 241.0 & 59.7 & $338.7 \pm 23.7 \mu \mathrm{g} \mathrm{CT} / \mathrm{g}$ fruit $\mathrm{dw}$ \\
\hline & $\mathrm{Y}_{2}$ & $\mathrm{C} 1$ & 18.6 & $100.0^{*}$ & $100.0^{*}$ & $62.0 \pm 2.6 \mu \mathrm{g} \mathrm{C} 1 / \mathrm{g} \mathrm{R}$ \\
\hline & & $\mathrm{C} 2$ & 21.2 & 222.2 & 63.6 & $345.3 \pm 29.8 \mu \mathrm{g} \mathrm{C} 2 / \mathrm{g} \mathrm{R}$ \\
\hline & & $\mathrm{C} 3$ & 19.9 & 181.9 & 70.2 & $82.3 \pm 9.7 \mu \mathrm{g} \mathrm{C} 3 / \mathrm{g} \mathrm{R}$ \\
\hline & & $\mathrm{CT}$ & 21.8 & 215.1 & 64.3 & $487.0 \pm 28.4 \mu \mathrm{g} \mathrm{CT} / \mathrm{g} \mathrm{R}$ \\
\hline \multicolumn{7}{|l|}{ B) Global optimal variable conditions } \\
\hline \multirow[t]{9}{*}{ Heat assisted extraction (HAE) } & Yield & & $20.0^{*}$ & $90.0^{*}$ & 65.4 & $62.8 \pm 6.6 \%$ \\
\hline & $\mathrm{Y}_{1}$ & $\mathrm{C} 1$ & & & & $39.1 \pm 4.5 \mu \mathrm{g} \mathrm{C} 1 / \mathrm{g}$ fruit $\mathrm{dw}$ \\
\hline & & $\mathrm{C} 2$ & & & & $236.5 \pm 25.1 \mu \mathrm{g} \mathrm{C} 2 / \mathrm{g}$ fruit $\mathrm{dw}$ \\
\hline & & $\mathrm{C} 3$ & & & & $54.0 \pm 6.1 \mu \mathrm{g} \mathrm{C} 3 / \mathrm{g}$ fruit $\mathrm{dw}$ \\
\hline & & $\mathrm{CT}$ & & & & $329.5 \pm 34.7 \mu \mathrm{g} \mathrm{CT} / \mathrm{g}$ fruit $\mathrm{dw}$ \\
\hline & $\mathrm{Y}_{2}$ & $\mathrm{C} 1$ & & & & $59.2 \pm 6.2 \mu \mathrm{g} \mathrm{C} 1 / \mathrm{g} \mathrm{R}$ \\
\hline & & $\mathrm{C} 2$ & & & & $364.5 \pm 38.2 \mu \mathrm{g} \mathrm{C} 2 / \mathrm{g} \mathrm{R}$ \\
\hline & & $\mathrm{C} 3$ & & & & $82.2 \pm 8.3 \mu \mathrm{g} \mathrm{C} 3 / \mathrm{g} \mathrm{R}$ \\
\hline & & $\mathrm{CT}$ & & & & $506.3 \pm 52.9 \mu \mathrm{g} \mathrm{CT} / \mathrm{g} \mathrm{R}$ \\
\hline \multirow[t]{9}{*}{ Ultrasound Assisted Extraction (UAE) } & Yield & & 27.4 & 243.7 & 59.9 & $79.97 \pm 9.2 \%$ \\
\hline & $\mathrm{Y}_{1}$ & $\mathrm{C} 1$ & & & & $42.2 \pm 5.7 \mu \mathrm{g} \mathrm{C} 1 / \mathrm{g}$ fruit $\mathrm{dw}$ \\
\hline & & $\mathrm{C} 2$ & & & & $240.6 \pm 26.1 \mu \mathrm{g} \mathrm{C} 2 / \mathrm{g}$ fruit $\mathrm{dw}$ \\
\hline & & $\mathrm{C} 3$ & & & & $55.8 \pm 6.3 \mu \mathrm{g} \mathrm{C} 3 / \mathrm{g}$ fruit $\mathrm{dw}$ \\
\hline & & CT & & & & $338.6 \pm 36.2 \mu \mathrm{g} \mathrm{CT} / \mathrm{g}$ fruit $\mathrm{dw}$ \\
\hline & $\mathrm{Y}_{2}$ & $\mathrm{C} 1$ & & & & $53.1 \pm 5.5 \mu \mathrm{g} \mathrm{C} 1 / \mathrm{g} \mathrm{R}$ \\
\hline & & $\mathrm{C} 2$ & & & & $338.7 \pm 36.8 \mu \mathrm{g} \mathrm{C} 2 / \mathrm{g} \mathrm{R}$ \\
\hline & & $\mathrm{C} 3$ & & & & $79.2 \pm 8.9 \mu \mathrm{g} \mathrm{C} 3 / \mathrm{g} \mathrm{R}$ \\
\hline & & $\mathrm{CT}$ & & & & $477.6 \pm 50.5 \mu \mathrm{g} \mathrm{CT} / \mathrm{g} \mathrm{R}$ \\
\hline
\end{tabular}

generated lower values. UAE maximal extractions values are accounted with optimal conditions within the rages studied in the $C C C D$, producing absolute optimal values. Meanwhile for the HAE case, the proposed optimal conditions show that shorter $t$ periods than those designed in the CCCD combined with high $T$ could favors the anthocyanins extraction. Since HAE was the technique that favors the extraction and based in the results presented in Fig. 3 part A, shorter $t$ periods with higher $T$ (over $90^{\circ} \mathrm{C}$ ), could potentially improve the responses obtained. Because of the strong interactive effects of $t S$ found in the RSM analyses (Table 2), three different levels of the variable $S$ were included (60, 80 and $100 \%$ of ethanol).

In consequence to depict the full potential of the HAE, a kinetic study using short to long $t$ periods (1-60 min) at the optimal $T$ of $90^{\circ} \mathrm{C}$ and three different $S$ values (60, 80 and $100 \%$ of ethanol) was conducted. Only the total anthocyanin content (CT) will be discussed, because the individual compound extraction ( $\mathrm{C} 1, \mathrm{C} 2$ or $\mathrm{C} 3$ ) behaved in similar mode. The data produced showed that shorter $t(\sim 5 \mathrm{~min})$ favors the extraction; shorter than $5 \mathrm{~min}$ would not be enough time to extract the total content in anthocyanins and $t$ values higher than 5 min would start to breakdown the compounds structure at any $S$ values at $90^{\circ} \mathrm{C}$. Several scenarios could be accepted as optimal values, but in an effort to produce acceptable conditions for industrial transference, $5 \mathrm{~min}$, $80 \%$ of ethanol and $90{ }^{\circ} \mathrm{C}$ is considered the most suitable values producing a response yield of $51.2 \%$ of the total fruit $\mathrm{dw}$, values corresponding to the total amount of compounds in the response format value of $Y_{1} 382.4 \mu \mathrm{g} \mathrm{CT} / \mathrm{g}$ fruit $\mathrm{dw}$, and $744.6 \mu \mathrm{g} \mathrm{CT} / \mathrm{g} R$ in the response format value $Y_{2}$. Compared to the values obtained in the RSM as relative optimum conditions, a reduction of the $\mathrm{R}$ extract produced, an increase of the proportion of ethanol needed (from 63 to 80\%) and an increase in the concentration of the total anthocyanins from 506.3 to $744.6 \mu \mathrm{g}$ CT/g R were observed.

The extraction of anthocyanins from $A$. unedo by HAE does not have a single optimal point, and several scenarios of $t(1-6 \mathrm{~min})$ and $S$ $\left(60-100 \%\right.$ of ethanol) at high $T\left(90^{\circ} \mathrm{C}\right)$ would produce a high concentrate response, which from an industrial point of view makes the anthocyanin extraction kinetics of this fruit a very peculiar and practical phenomenon.

\subsection{Dose-response analysis of the solid-to-liquid effect at the optimum conditions}

The ideal amount of solvent should be just enough to dissolve the targeted compounds (Albuquerque et al., 2016). The structure of the matrix will affect the ability of the solvent to permeate and extract the desired compounds (Pinela et al., 2017). Therefore, a study aiming to evaluate the $S / L$ effect was conducted at the global optimal conditions predicted by the polynomial models obtained for HAE and UAE techniques. 
Based in preliminary results, the dose-response process of extraction was designed to verify the $S / L$ patterns in the range $5 \mathrm{~g} / \mathrm{L}-150 \mathrm{~g} / \mathrm{L}$. The $S / L$ effect can be described by a simple non-linear relationship using Eq. (2). The effects of the $S / L$ dose-response in HAE and UAE are presented in Fig. 3B for all response criteria, but only in reference to total anthocyanin content (CT); since it is expected that the extraction of the individual anthocyanins (C1, C2 or C3) follow the same trend. In all cases, the responses obtained through the HAE and UAE systems are consistent with the previous results. The $S / L$ increase leads to a decrease in the extraction ability of the solvent; consequently, the extraction responses reach a maximum value at minimum values of $S / L$ and a minimum at higher values of $S / L$, and the respective losses are justified by parametric results derived from Eqs. (2) and (3). In this regard, the results obtained for the HAE and UAE in terms of the response criterion $Y_{1}(\mu \mathrm{g} / \mathrm{g}$ of fruit $\mathrm{dw})$ are as follows.

- For the HAE system: the value of $K$ that accounts for the maximum value achieved was found to be $500.9 \pm 22.1 \mu \mathrm{g} / \mathrm{g}$ of fruit $\mathrm{dw}$; the value of $m$ that accounts for the $S / L$ value that provides $50 \%$ of the parameter value $K$ was found to be $98.9 \pm 11.7 \mathrm{~g}$ fruit $\mathrm{dw} / \mathrm{L}$; the value of $v$ that provides the decreasing average rate of process was found to be $1.16 \pm 0.21 \mu \mathrm{g} / \mathrm{g}$ of fruit $\mathrm{dw}$; the coefficient of determination $\mathrm{R}^{2}$ achieved was 0.9471 ; and the dimensionless shape parameter $a$ was found to be $0.66 \pm 0.11$.

- For UAE response: $K=348.6 \pm 21.5 \mu \mathrm{g} / \mathrm{g}$ of fruit $\mathrm{dw}$; $m=122.8 \pm 8.5 \mathrm{~g}$ fruit dw/L; $v=3.16 \pm 0.63 \mu \mathrm{g} / \mathrm{g}$ of fruit $\mathrm{dw} / \mathrm{L}$; $\mathrm{R}^{2}=0.9411 ;$ and $a=3.21 \pm 0.83$.

In terms of the response criterion $Y_{2}(\mu \mathrm{g} / \mathrm{g}$ of $\mathrm{R})$ are as follows:

- For HAE response: $K=800.6 \pm 31.5 \mu \mathrm{g} / \mathrm{g} \quad$ of $\quad \mathrm{R}$; $m=104.5 \pm 10.2 \mathrm{~g}$ fruit $\mathrm{dw} / \mathrm{L} ; v=1.73 \pm 0.17 \mu \mathrm{g} / \mathrm{g}$ of $\mathrm{R}$ per $\mathrm{g}$ fruit dw/L; $\mathrm{R}^{2}=0.9102$; and $a=0.65 \pm 0.13$.

- For UAE response: $K=499.2 \pm 70.1 \mu \mathrm{g} / \mathrm{g}$ of $\mathrm{R}$; $m=127.0 \pm 41.3 \mathrm{~g}$ fruit $\mathrm{dw} / \mathrm{L} ; v=4.32 \pm 0.96 \mu \mathrm{g} / \mathrm{g}$ of $\mathrm{R}$ per $\mathrm{g}$ fruit dw/L; $\mathrm{R}^{2}=0.9490$; and $a=3.17 \pm 1.01$.

In terms of the response criterion of yield are as follows (note that only the parameter $\mathrm{K}$ showed significant values due to the lack of changes of the response as a function of the $S / L$ variable):

- For HAE response: $K=60.9 \pm 10.3 \%$ with a $\mathrm{R}^{2}=0.9954$.

- For UAE response: $K=66.8 \pm 6.5 \%$ with a $\mathrm{R}^{2}=0.9940$.

In statistical terms, the mathematical model of Eqs. (2) and (3) used to assess non-linear $S / L$ trends showed highly significant parameters for all techniques, a fact that was also verified by the achieved high $\mathrm{R}^{2}$ values, indicating the good agreement of the model with the produced experimental results. From this parametric analysis, the different trends of the $S / L$ effect can be determined at the optimal extraction conditions achieved for each one of the assessed techniques by means of the most relevant parameters $(K, m$ and $v)$.

In conclusion, it can be observed that HAE is the technique were higher CT yields were achieved in the $S / L$ interval range of $5-40 \mathrm{~g} / \mathrm{L}$, as corroborated by the higher values of parameter $K$. The decrease observed with UAE system is slightly higher than the one observed with HAE, as noted by the parameters $m$ and $v$. Also, HAE is more efficient to extract CT at $S / L$ ranges of 50 to $150 \mathrm{~g} / \mathrm{L}$. The higher loss induced by the increase of $S / L$ in the UAE highlights that the extraction yields are more efficient in HAE system. A similar behavior was found for the other response criteria ( $Y_{2}$ and yield).

\subsection{Comparison with other studies involving the extraction of anthocyanins}

Although the use of strawberry-tree fruits is currently not widespread, perhaps due to the lack of dedicated cultivars and to the fact that fruits flavor is only perceived as agreeable if consumed overripe. Consequently, the scientific information on the chemical profiles (composition and concentration) of this matrix is scarce. Anthocyanins can be present in all plants parts, although they are mostly found in fruits, vegetables and flowers, where they are responsible for a wide range of colors (Casedas et al., 2017; Khadhraoui et al., 2018). The anthocyanins content varies widely in similar fruit samples, from $\sim 20 \mu \mathrm{g} / \mathrm{g}$ of fruit dw (plum) to $\sim 15000 \mu \mathrm{g} / \mathrm{g}$ of fruit dw (elderberry) (Clifford, 2000).

The total optimized anthocyanins content in strawberry-tree fruits obtained in this work is $\sim 500 \mu \mathrm{g} / \mathrm{g}$ of fruit $\mathrm{dw}$ or $\sim 800 \mu \mathrm{g} / \mathrm{g}$ of $\mathrm{R}$. These results are within the same range of well-known fruits with high anthocyanins contents, such as Nitraria tangutorum Bobr. $(\sim 650 \mu \mathrm{g} / \mathrm{g}$ of fruit dw) (Sang, Sang, Ma, Hou, \& Li, 2017) and Aristotelia chilensis L. (400-1500 $\mu \mathrm{g} / \mathrm{g}$ of fruit dw) (Gironés-Vilaplana et al., 2014). In addition, the anthocyanins content in strawberry-tree fruits is similar to the one of chalices of Hibiscus sabdariffa L. (300 to $1250 \mu \mathrm{g} / \mathrm{g}$ of plant dw) (Salazar-González et al., 2012). Comparatively to fruits, seeds and tubers, although there are exceptions, usually give rise to lower anthocyanins yields. This is the case of Vitis vinifera $\mathrm{L}$., whose values are around $\sim 25 \mu \mathrm{g} / \mathrm{g}$ of seeds dw (Ghafoor, Choi, Jeon, \& Jo, 2009) or tubers of Ipomoea batatas L., which barely reach $\sim 300 \mu \mathrm{g} / \mathrm{g}$ of tubers dw (Zhu et al., 2017).

\section{Conclusions}

Anthocyanin compounds have gathered attention from the scientific and industrial communities due to their vast range of possible applications, including the use as food coloring and functional additives in foodstuffs. As secondary plant metabolites, the attainment of anthocyanins is approached mainly through solid-liquid extraction techniques from plant tissues. Given the widespread interest for anthocyanins, there has been an effort to modernize the extraction protocols, reducing the amount of organic solvents (ecological point of view) and improving the extraction yield (economic point of view). The lack of optimization approaches, specifically in what concerns anthocyanins extraction contributed to detract the use of these natural solutions in food industry.

Therefore, the present study aimed to optimize anthocyanins extraction from $A$. unedo fruits using affordable extraction techniques, easy to use and to apply at industrial level, namely to obtain natural colorant agents with interest for food, pharmaceutical and cosmetic industries. Two extraction methodologies (HAE and UAE) were studied and compared. The joint effect of the relevant variables for each technique, to maximize anthocyanin extraction, was described through RSM analysis, contributing for a better understanding of the real potential of anthocyanin production from $A$. unedo. The most effective technique was $\mathrm{HAE}$ at $5 \mathrm{~min}, 90^{\circ} \mathrm{C}$ and $80 \%$ of acidified ethanol within a $S / L$ range of 5 to $40 \mathrm{~g} / \mathrm{L}$, obtaining a residual extract of $\sim 60 \%$ of the total fruit dw, with a total anthocyanins content of $\sim 500 \mu \mathrm{g} / \mathrm{g}$ of fruit $\mathrm{dw}$ or $\sim 800 \mu \mathrm{g} / \mathrm{g}$ of $\mathrm{R}$ extract residue.

\section{Acknowledgements}

The authors are grateful to the Foundation for Science and Technology (FCT, Portugal) and FEDER under Programme PT2020 for financial support to CIMO (UID/AGR/00690/2013), LA LSRE-LCM (POCI-01-0145-FEDER-006984), L. Barros contract and C. Caleja (SFRH/BD/93007/2013) grant. This work is funded by the European Structural and Investment Funds (FEEI) through the Regional Operational Program North 2020, within the scope of Project NORTE01-0145-FEDER-023289: DeCodE and project Mobilizador Norte-010247-FEDER-024479: ValorNatural ${ }^{\oplus}$. The authors are also grateful to FEDER-Interreg España-Portugal programme for financial support through the project 0377_Iberphenol_6_E. To Xunta de Galicia for financial support for the post-doctoral researcher of M.A. Prieto. 


\section{Appendix A. Supplementary data}

Supplementary data associated with this article can be found, in the online version, at http://dx.doi.org/10.1016/j.foodchem.2018.04.103.

\section{References}

Albuquerque, B. R., Prieto, M. A., Barreiro, M. F., Rodrigues, A., Curran, T. P., Barros, L., \& Ferreira, I. C. F. R. (2016). Catechin-based extract optimization obtained from Arbutus unedo L. fruits using maceration/microwave/ultrasound extraction techniques. Industrial Crops and Products, 95, 404-415.

Bezerra, M. A., Santelli, R. E., Oliveira, E. P., Villar, L. S., Escaleira, E. A., \& Escaleira, L. A. (2008). Response surface methodology (RSM) as a tool for optimization in analytical chemistry. Talanta, 76(5), 965-977.

Carocho, M., Barreiro, M. F., Morales, P., \& Ferreira, I. C. F. R. (2014). Adding molecules to food, pros and cons: A review on synthetic and natural food additives. Comprehensive Reviews in Food Science and Food Safety, 13(4), 377-399.

Carocho, M., Morales, P., \& Ferreira, I. C. F. R. (2015). Natural food additives: Quo vadis? Trends in Food Science \& Technology, 45, 284-295.

Casedas, G., Les, F., Gomez-Serranillos, M. P., Smith, C., \& Lopez, V. (2017). Anthocyanin profile $\{$,$\} antioxidant activity and enzyme inhibiting properties of blueberry and$ cranberry juices: A comparative study. Food Funct. 8(11), 4187-4193.

Castañeda-Ovando, A., de Pacheco-Hernández, M. de L., Páez-Hernández, M. E., Rodríguez, J. A., \& Galán-Vidal, C. A. (2009). Chemical studies of anthocyanins: A review. Food Chemistry, 113(4), 859-871.

Cavalcanti, R. N., Santos, D. T., \& Meireles, M. A. A. (2011). Non-thermal stabilization mechanisms of anthocyanins in model and food systems-An overview. Food Research International, 44(2), 499-509.

Chemat, F., Rombaut, N., Meullemiestre, A., Turk, M., Perino, S., Fabiano-Tixier, A. S., \& Abert-Vian, M. (2017). Review of Green Food Processing techniques. Preservation, transformation, and extraction. Innovative Food Science and Emerging Technologies, 41, 357-377.

Chemat, F., Rombaut, N., Sicaire, A. G., Meullemiestre, A., Abert-vian, M., Fabiano-Tixier, A. S., \& Abert-vian, M. (2017). Ultrasonics Sonochemistry Ultrasound assisted extraction of food and natural products. Mechanisms, techniques, combinations, protocols and applications. A review. Ultrasonics - Sonochemistry, 34, 540-560.

Chemat, F., Zill-E-Huma, \& Khan, M. K. (2011). Applications of ultrasound in food technology: Processing, preservation and extraction. Ultrasonics Sonochemistry, 18(4), 813-835.

Chen, M., Zhao, Y., \& Yu, S. (2015). Optimisation of ultrasonic-assisted extraction of phenolic compounds, antioxidants, and anthocyanins from sugar beet molasses. Food Chemistry, 172, 543-550.

Choi, Y. H., van Spronsen, J., Dai, Y., Verberne, M., Hollmann, F., Arends, I. W. C. E., ... Verpoorte, R. (2011). Are natural deep eutectic solvents the missing link in understanding cellular metabolism and physiology? Plant Physiology, 156, 1701-1705.

Choung, M., Baek, I., Kang, S., Han, W., \& Shin, D. (2001). Isolation and determination of anthocyanins in seed coats of black soybean (Glycine $\max (\mathrm{L}$.) Merr.). Journal of Agricultural and Food Chemistry, 18, 5848-5851.

Cimino, F., Ambra, R., Canali, R., Saija, A., \& Virgili, F. (2006). Effect of cyanidin-3-Oglucoside on UVB-induced response in human keratinocytes. Journal of Agricultural and Food Chemistry, 54(11), 4041-4047.

Clifford, M. N. (2000). Anthocyanins - nature, occurrence and dietary burden. Journal of the Science of Food and Agriculture, 80(7), 1063-1072.

Comuzzi, C., Polese, P., Melchior, A., Portanova, R., \& Tolazzi, M. (2003). SOLVERSTAT: A new utility for multipurpose analysis. An application to the investigation of dioxygenated Co (II) complex formation in dimethylsulfoxide solution. Talanta, 59(1), 67-80.

Elisia, I., Hu, C., Popovich, D. G., \& Kitts, D. D. (2006). Antioxidant assessment of an anthocyanin-enriched blackberry extract. Food Chemistry, 101(3), 1052-1058.

Ferreira, S. L. C., Bruns, R. E., Ferreira, H. S., Matos, G. D., David, J. M., Brandão, G. C., .. dos Santos, W. N. L. (2007). Box-Behnken design: An alternative for the optimization of analytical methods. Analytica Chimica Acta, 597(2), 179-186.

Ghafoor, K., Choi, Y. H., Jeon, J. Y., \& Jo, I. H. (2009). Optimization of ultrasoundassisted extraction of phenolic compounds, antioxidants, and anthocyanins from grape (Vitis vinifera) seeds. Journal of Agricultural and Food Chemistry, 57(11), 4988-4994.

Gironés-Vilaplana, A., Baenas, N., Villaño, D., Speisky, H., García-Viguera, C., \& Moreno, D. A. (2014). Evaluation of Latin-American fruits rich in phytochemicals with biological effects. Journal of Functional Foods, 7(1), 599-608.

Gonçalves, G. A., Soares, A. A., Correa, R. C. G., Barros, L., Haminiuk, C. W. I., Peralta, R. M., ... Bracht, A. (2017). Merlot grape pomace hydroalcoholic extract improves the oxidative and inflammatory states of rats with adjuvant-induced arthritis. Journal of Functional Foods, 33, 408-418.

Guimarães, R., Barros, L., Dueñas, M., Carvalho, A. M., Queiroz, M. J. R. P., SantosBuelga, C., \& Ferreira, I. C. F. R. (2013). Characterisation of phenolic compounds in wild fruits from Northeastern Portugal. Food Chemistry, 141, 3721-3730.

Heleno, S. A., Prieto, M. A., Barros, L., Rodrigues, A. A., Barreiro, M. F., \& Ferreira, I. C. F. R. (2016). Optimization of microwave-assisted extraction of ergosterol from Agaricus bisporus L. by-products using response surface methodology. Food and Bioproducts Processing, 100, 25-35.

Jacotet-Navarro, M., Rombaut, N., Deslis, S., Fabiano-Tixier, A.-S., Pierre, F.-X., Bily, A. \& Chemat, F. (2016). Towards a "dry" bio-refinery without solvents or added water using microwaves and ultrasound for total valorization of fruit and vegetable byproducts. Green Chemistry, 18(10), 3106-3115.

Kemmer, G., \& Keller, S. (2010). Nonlinear least-squares data fitting in Excel spreadsheets. Nature Protocols, 5(2), 267-281.

Khadhraoui, B., Turk, M., Fabiano-Tixier, A. S., Petitcolas, E., Robinet, P., Imbert, R., .. Chemat, F. (2018). Histo-cytochemistry and scanning electron microscopy for studying spatial and temporal extraction of metabolites induced by ultrasound. Towards chain detexturation mechanism. Ultrasonics Sonochemistry, 42, 482-492.

Lambot, S., Slob, E. C., Den Van Bosch, I., Stockbroeckx, B., \& Vanclooster, M. (2004) Modeling of ground-penetrating radar for accurate characterization of subsurface electric properties. IEEE Transactions on Geoscience and Remote Sensing, 42(11), 2555-2568.

Lee, J. H., Lee, H. J., \& Choung, M. G. (2011). Anthocyanin compositions and biological activities from the red petals of Korean edible rose (Rosa hybrida cv. Noblered). Food Chemistry, 129(2), 272-278.

Martins, N., Roriz, C. L., Morales, P., Barros, L., \& Ferreira, I. C. F. R. (2016). Food colorants: Challenges, opportunities and current desires of agro-industries to ensure consumer expectations and regulatory practices. Trends in Food Science and Technology, 52, 1-15.

Mojica, L., Berhow, M., \& Gonzalez de Mejia, E. (2017). Black bean anthocyanin-rich extracts as food colorants: Physicochemical stability and antidiabetes potential. Food Chemistry, 229, 628-639.

Murado, M. A., \& Prieto, M. A. (2013). Dose-response analysis in the joint action of two effectors. A New approach to simulation, identification and modelling of some basic interactions. PLOS ONE, 8(4), e61391.

Piñeiro, Z., Palma, M., \& Barroso, C. G. (2004). Determination of catechins by means of extraction with pressurized liquids. Journal of Chromatography A, 1026(1-2), 19-23.

Pinela, J., \& Ferreira, I. C. F. R. (2017). Nonthermal physical technologies to decontaminate and extend the shelf-life of fruits and vegetables: Trends aiming at quality and safety. Critical Reviews in Food Science and Nutrition, 57(10), 2095-2111.

Pinela, J., Prieto, M. A., Barreiro, M. F., Carvalho, A. M., Oliveira, M. B. P. P., Curran, T. P., \& Ferreira, I. C. F. R. (2017). Valorisation of tomato wastes for development of nutrient-rich antioxidant ingredients: A sustainable approach towards the needs of the today's society. Innovative Food Science and Emerging Technologies, 41, 160-171.

Pinela, J., Prieto, M. A., Carvalho, A. M., Barreiro, M. F., Oliveira, M. B. P., Barros, L., \& Ferreira, I. C. F. R. (2016). Microwave-assisted extraction of phenolic acids and flavonoids and production of antioxidant ingredients from tomato: A nutraceutical-oriented optimization study. Separation and Purification Technology, 164, 114-124.

Pingret, D., Fabiano-Tixier, A.-S., Bourvellec, C. Le, Renard, C. M. G. C., \& Chemat, F. (2012). Lab and pilot-scale ultrasound-assisted water extraction of polyphenols from apple pomace. Journal of Food Engineering, 111(1), 73-81.

Prieto, M. A., Curran, T. P., Gowen, A., \& Vázquez, J. A. (2015). An efficient methodology for quantification of synergy and antagonism in single electron transfer antioxidant assays. Food Research International, 67, 284-298.

Prikler, S. (2009). Advanced Excel for scientific data analysis ((2nd ed.)). Robert de Levie Ed.

Rodrigues, S., Fernandes, F. A. N., de Brito, E. S., Sousa, A. D., \& Narain, N. (2015). Ultrasound extraction of phenolics and anthocyanins from jabuticaba peel. Industrial Crops and Products, 69, 400-407.

Salazar-González, C., Vergara-Balderas, F. T., Ortega-Regules, A. E., \& Beltrán, J.Á. (2012). Antioxidant properties and color of Hibiscus sabdariffa extracts. Ciencia E Investigación Agraria, 39(1), 79-90.

Sang, J. J., Sang, J. J., Ma, Q., Hou, X Fang, \& Li, C Qin (2017). Extraction optimization and identification of anthocyanins from Nitraria tangutorun Bobr. seed meal and establishment of a green analytical method of anthocyanins. Food Chemistry, 218, 386-395.

Shi, P., \& Tsai, C.-L. (2002). Regression Model Selection: A Residual Likelihood Approach. Journal of the Royal Statistical Society.Series B (Statistical Methodology), 64(2), 237-252.

Silva, S., Costa, E. M., Calhau, C., Morais, R. M., \& Pintado, M. E. (2017). Anthocyanin extraction from plant tissues: A review. Critical Reviews in Food Science and Nutrition, 57(14), 3072-3083.

Vieira, V., Prieto, M. A., Barros, L., Coutinho, J. A. P., Ferreira, O., \& Ferreira, I. C. F. R. (2017). Optimization and comparison of maceration and microwave extraction systems for the production of phenolic compounds from Juglans regia L. for the valorization of walnut leaves. Industrial Crops and Products, 107.

Vuong, Q. V., Golding, J. B., Nguyen, M., \& Roach, P. D. (2010). Extraction and isolation of catechins from tea. Journal of Separation Science, 33(21), 3415-3428.

Wang, L., \& Weller, C. L. (2006). Recent advances in extraction of nutraceuticals from plants. Trends in Food Science and Technology, 17(6), 300-312.

Wissgott, U., \& Bortlik, K. (1996). Prospects for new natural food colorants. Trends in Food Science \& Technology, 7(9), 298-302.

Zhu, Z., Guan, Q., Koubaa, M., Barba, F. J., Roohinejad, S., Cravotto, G., ... He, J. (2017). HPLC-DAD-ESI-MS2 analytical profile of extracts obtained from purple sweet potato after green ultrasound-assisted extraction. Food Chemistry, 215, 391-400. 